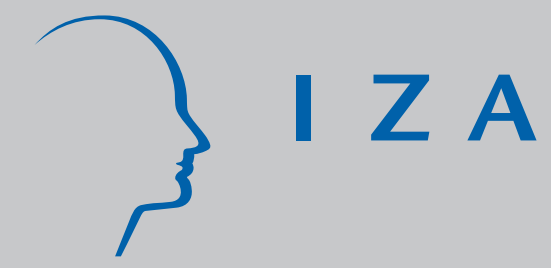

IZA DP No. 7991

The Firm Size Distribution across Countries and Skill-Biased Change in Entrepreneurial Technology

Markus Poschke

February 2014 


\title{
The Firm Size Distribution across Countries and Skill-Biased Change in Entrepreneurial Technology
}

\author{
Markus Poschke \\ McGill University, CIREQ \\ and IZA
}

Discussion Paper No. 7991

February 2014

\author{
IZA \\ P.O. Box 7240 \\ 53072 Bonn \\ Germany \\ Phone: +49-228-3894-0 \\ Fax: +49-228-3894-180 \\ E-mail: iza@iza.org
}

\begin{abstract}
Any opinions expressed here are those of the author(s) and not those of IZA. Research published in this series may include views on policy, but the institute itself takes no institutional policy positions. The IZA research network is committed to the IZA Guiding Principles of Research Integrity.

The Institute for the Study of Labor (IZA) in Bonn is a local and virtual international research center and a place of communication between science, politics and business. IZA is an independent nonprofit organization supported by Deutsche Post Foundation. The center is associated with the University of Bonn and offers a stimulating research environment through its international network, workshops and conferences, data service, project support, research visits and doctoral program. IZA engages in (i) original and internationally competitive research in all fields of labor economics, (ii) development of policy concepts, and (iii) dissemination of research results and concepts to the interested public.
\end{abstract}

IZA Discussion Papers often represent preliminary work and are circulated to encourage discussion. Citation of such a paper should account for its provisional character. A revised version may be available directly from the author. 


\title{
ABSTRACT
}

\section{The Firm Size Distribution across Countries and Skill-Biased Change in Entrepreneurial Technology ${ }^{*}$}

\begin{abstract}
How and why does the firm size distribution differ across countries? Using two datasets covering more than 30 countries, this paper documents that several features of the firm size distribution are strongly associated with income per capita: the entrepreneurship rate and the fraction of small firms fall with per capita income across countries, while average firm employment, the median and higher percentiles of the firm size distribution, and the dispersion and skewness of employment all rise with per capita income. The paper broadens existing evidence on the first three facts to cover more countries and newly introduces the last three to the literature. It then proposes a simple theory of skill-biased change in entrepreneurial technology motivated by recent microeconomic literature that fits with the evidence. For this, it introduces two additional features into an otherwise standard occupational choice, heterogeneous firm model à la Lucas (1978): technological change does not benefit all potential entrepreneurs equally, and there is a positive relationship between an individual's potential payoffs in working and in entrepreneurship. If some firms consistently benefit more from technological progress than others, they stay closer to the frontier, while others fall behind. Because wages rise for all workers, marginal entrepreneurs exit and become workers. Quantitatively, the model fits both the U.S. time series experience and cross-country patterns well.
\end{abstract}

JEL Classification: E24, J24, L11, L26, O30

Keywords: occupational choice, entrepreneurship, firm size, skill-biased technical change

Corresponding author:

Markus Poschke

McGill University

Economics Department

855 Sherbrooke St West

Montreal QC H3A 2T7

Canada

E-mail: markus.poschke@mcgill.ca

\footnotetext{
* I would like to thank Francisco Alvarez-Cuadrado, Rui Castro, Russell Cooper, Chad Jones, Bart Hobijn, Pete Klenow, Mariacristina De Nardi, Tapio Palokangas, Ayşegül Şahin, Roberto Samaniego and seminar participants at the Federal Reserve Banks of Chicago, San Francisco, New York and Philadelphia, at the World Bank, Carleton University, McGill University, George Washington University, York University, the University of Barcelona, the Université de Montréal macro brownbag, the XXXIV Simposio de Análisis Económico (Valencia 2009), the Society for Economic Dynamics 2010 Meeting in Montreal, the 7th Meeting of German Economists Abroad (Frankfurt 2010), the Cirpée-Ivey Conference on Macroeconomics and Entrepreneurship (Montréal 2011), the European Economic Review Young Economist Workshop (Bonn 2011), the CESifo Conference on Macroeconomics and Survey Data (Munich 2011), the Canadian Macro Study Group (Vancouver 2011), and LACEA (Lima 2012) for valuable comments and suggestions, Lori Bowan at the U.S. Census Bureau for providing a detailed tabulation of firm size counts and Steven Hipple at the Bureau of Labor Statistics for providing information on employment by the self-employed. I gratefully acknowledge financial support from the Fonds de la recherche sur la société et la culture and from the Social Sciences and Humanities Research Council.
} 


\section{Introduction}

How and why does the firm size distribution differ across countries and within country over time? Within the growing body of recent work on the firm size distribution (see e.g. Samaniego 2006, Gollin 2007, Restuccia and Rogerson 2008, Hsieh and Klenow 2009), most papers study the distribution in one or few countries at a single point in time. As a consequence, little is known about broad cross-country patterns. This paper documents a particular set of first order features of the cross-country data: changes in the firm size distribution with development. It documents how the firm size distribution differs across countries with different income levels and in U.S. history and then proposes a simple theory that is consistent with these patterns.

Governments in many countries spend resources to encourage the formation and to subsidize the operation of small businesses (for example the Small Business Administration's Advantage Loan Initiatives in the U.S. and the "Ich-AG" ("Me, Inc.") scheme in Germany), while at the same time, often implicitly, promoting large companies ("national champions"). In advocating such policies, often comparisons are drawn to firm size distributions in other places (e.g. "dynamic" emerging markets with many small firms), without much knowledge of the patterns to expect when comparing firm size distributions across countries. Information on patterns in firm size distributions across countries and on their determinants therefore provides a valuable baseline for putting such statements in perspective.

Comparing firm size distributions across countries is a challenge because of a lack of harmonized data. Overcoming this problem is the first main contribution of this paper. To do so, I use data from two sources designed with comparability across countries in mind. The first, which is particularly strong at capturing small firms, is the Global Entrepreneurship Monitor (GEM), a survey conducted in around 50 countries that focusses on obtaining internationally comparable information on entrepreneurs. The second, which focusses on large firms, is the Amadeus database collected by Bureau van Dijk (BvD). Together, they cover the size distribution well. In addition, I use historical U.S. data. To the best of my knowledge, this is the first paper using information from the GEM for general equilibrium analysis, and one of the first to use Amadeus in such a context. Section 2 uses this data to review and extend to a broader cross-section three known facts about the firm size distributions and to establish three new facts. The findings are: First, the entrepreneurship rate falls with per capita income across countries. Second, the importance of small firms also falls with per capita income. Third, average firm employment increases with per capita income. The first fact fits with the finding of Gollin (2007) that the self-employment rate falls with per capita income in ILO cross-country data. The second one has appeared, often based 
on less comprehensive data, in the development literature (e.g. Beck, Demirgüç-Kunt and Maksimovic 2004). The third one extends Lucas's (1978) results to more recent U.S. data and into the cross-country dimension. The next three facts are new: Fourth, the median and higher percentiles of the firm employment distribution increase with per capita income across countries. Fifth, so does the standard deviation of firm size. Sixth, the skewness of the firm size distribution also increases with per capita income across countries. Establishing these facts using two datasets that together cover the entire firm size spectrum in a large number of countries is an important contribution. ${ }^{1}$

The data thus show a relationship between the level of development and features of the firm size distribution. Lucas (1978), Gollin (2007), Akyol and Athreya (2009) and Roys and Seshadri (2013) provide explanations for facts one and three, but their models do not fit the other facts. In particular, they all tend to predict less size dispersion in richer economies. The new facts thus matter, since they help discriminate among theories. This paper shows that all six facts can be explained in an otherwise standard occupational choice model à la Lucas (1978) with two additional features: technological change not benefitting all potential entrepreneurs equally, and a positive relationship between an individual's potential payoffs in working and in entrepreneurship.

I call the first feature skill-biased change in entrepreneurial technology. It is remarkable that in contrast to the very large literature on skill-biased technical change among workers, there is hardly any work on the importance of skills for the entrepreneurs who employ those workers, and in particular on their evolution over time. Technological change is taken for granted as the main historical driver of growth in developed economies. In the recent literature, several types of technological change apart from the neutral variety have received a lot of attention (see e.g. Greenwood, Hercowitz and Krusell (1997) on investment-specific technological change, Krusell, Ohanian, Rios-Rull and Violante (2000) on capital-skill complementarity, Katz and Murphy (1992) on skill-biased technical change and the demand for workers or Hornstein, Krusell and Violante (2005) on links among the three). However, there has been barely any work on how technological change affects entrepreneurs. Yet, entrepreneurs need to implement the technologies that they and their employees then operate, so the effect of technical change on entrepreneurs is of crucial importance for how technology subsequently affects labor demand, wages and employment.

\footnotetext{
${ }^{1}$ Other work on the firm size distribution, like Alfaro, Charlton and Kanczuk (2008) and García-Santana and Ramos (2013), based on Dun \& Bradstreet data and the World Bank Enterprise Surveys, respectively, could by construction not cover the entire size distribution. The World Bank Enterprise Surveys do not cover the informal sector, and Dun \& Bradstreet data tend to oversample large firms, in particular in poorer countries where their coverage is thinner. The well-known paper Hsieh and Klenow (2009) also has limited coverage of small firms; see footnote 19 for a detailed discussion.
} 
In the simple theory of skill-biased change in entrepreneurial technology proposed here, aggregate technology affects occupational choice of entrepreneurs and thus the firm size distribution. When calibrated to U.S. data, the model is consistent with the cross-country evidence on the firm size distribution and development.

Anyone who has programmed a VCR or tried to set up a home computing network will appreciate that while technological progress brings productivity advances, it often goes along with increased complexity of technology. This is even more so for firms, and not just for large or "high-tech" ones. Consider the corner shop owner contemplating the installation of bar code scanners. This allows automating inventory control, but requires managing the related computing infrastructure. Or consider the owner of a car repair shop who needs to master the increasing amount of computing power of customers' cars. This allows for faster diagnostic checks, but also requires mastering technology that is quite distinct from the core technologies used in that business. ${ }^{2}$

As the menu of available technologies expands, raising aggregate productivity (assuming love of variety, as in Romer 1987), individual firms have to cope with increasing complexity of technology. To reflect this, the key assumption in the model, which otherwise is a standard occupational choice model à la Lucas (1978), is that, while advances in the technological frontier give all firms access to a more productive technology, they do not affect all firms equally. Some firms can implement new technologies at lower cost, and therefore take more advantage of them. As a result, some firms remain close to the frontier and use a production process involving many, highly specialized inputs, while others fall behind the frontier, use a simpler production process, and fall behind in terms of relative productivity. ${ }^{3}$

The second crucial assumption is that agents differ in their labor market opportunities and that more productive workers can also manage more complex technologies if they become entrepreneurs. Occupational choice between employment and entrepreneurship closes the model. Because advances in the technological frontier do not benefit every potential entrepreneur equally, the position of the frontier then governs occupational choice. The

\footnotetext{
${ }^{2}$ Jovanovic and Rousseau (2008) document that from 1971 to 2006, the average yearly growth rates of the stocks of patents and trademarks in the U.S. were $1.9 \%$ and $3.9 \%$, respectively, implying a substantial increase in variety. Michaels (2007) computes an index of complexity based on the variety of occupations employed in an industry. He shows that complexity in U.S. manufacturing has increased substantially over the past one and a half century, and that complexity was higher in the U.S. than in Mexico. Similarly, every new classification of occupations in the U.S. from 1970 to 2010 lists more occupations than the preceding one (Scopp 2003).

${ }^{3}$ At the same time, Cummins and Violante (2002) find that the gap between the frontier and average technology in use has been increasing in the U.S. over the entire span of their data (1947-2000), implying that firms have not all benefitted equally from technology improvements. Similarly, Bloom, Sadun and Van Reenen (2012) find that gains from the introduction of information technology differed both across firms and across countries.
} 
more advanced the frontier, the greater the benefit from being able to stay close to it, as other firms fall behind. Because in equilibrium, advances in the frontier also raise wages, entrepreneurs' outside option improves, and marginal entrepreneurs exit. The result is a "history", explored in Section 4, in which high-productivity firms gradually expand their operations as their productivity improves more than others'. Their entry and growth raise labor demand and the wage, implying that low-productivity entrepreneurs eventually find employment more attractive and exit. ${ }^{4}$ This in turn affects the firm size distribution, implying that the model matches Facts 1 to 5 quite generally, and Fact 6 in the quantitative exercise that follows. For this analysis of occupational choice and the firm size distribution, capturing the existence and motives of low-productivity entrepreneurs - typically neglected in the firm dynamics literature - is key, in particular given that they are so abundant in poor countries.

The need for skills to deal with a broad array of technologies at the same time is in line with Lazear's $(2004,2005)$ finding that entrepreneurs tend to have more general skills than employees. It also fits with evidence from the burgeoning recent literature on CEOs and CEO pay, which shows that the importance of general skills has risen of late (see e.g. Murphy and Zabojnik 2004, Rajan and Wulf 2006, Frydman 2007). ${ }^{5}$ These skills are usually measured as the variety of someone's experience of different industries, companies, functions within companies (e.g. production, marketing, finance), and thus technologies. The main reasons for this phenomenon suggested by that literature are a growing need to master more technologies at the same time and broader responsibilities that come from flatter hierarchies made possible by advancing information technology. If entrepreneurs want to benefit from the new possibilities put on the menu by technological advances, they need to keep up with technological developments. The degree to which they can do so determines how much benefit they reap from technological progress. ${ }^{6}$

\footnotetext{
${ }^{4}$ As there is an across-the-board productivity increase in the model as the frontier advances, it also allows for certain tasks that used to be at the technological frontier to be achieved by entrepreneurs behind the frontier as technological advances. Think e.g. about multimedia; a professional can now do on a single computer what in earlier times would have required much more resources. Yet, the frontier moves on - the professional benefits, but entrepreneurs closer to the frontier now can use even more advanced technology.

${ }^{5}$ Of course, CEOs and entrepreneurs do not fulfill exactly the same functions. Still, their job content is similar, with the main difference being the importance of the willingness to take risk. As this will not play a prominent role in this paper, CEOs are an informative group of comparison.

${ }^{6}$ This is qualitatively different from the need for employees to keep up with technology: employees need to apply a given technology, while entrepreneurs need to choose and coordinate the technologies used in a firm's production process. So even if technological progress had de-skilling elements in the 19th century, as argued by James and Skinner (1985) and by Cain and Paterson (1986), replacing skilled workers with machinery still made increasing demands on entrepreneurs to understand and coordinate the new technologies that now were available in addition to the old ones. The setting here thus does not depend on complementarity between capital and workers' skills; all that is needed is that keeping up with advancing technology is costly
} 
While the effects of this development on organizational hierarchies and CEO pay have received a lot of attention recently, ${ }^{7}$ the general equilibrium implications have not been studied. ${ }^{8}$ Yet, they are substantial, as incentives for entrepreneurship determine not just individual occupational choice and entrepreneurs' incomes, but also aggregate labor demand, the level of aggregate technology that is actually in place, output and, of course, the firm size distribution. Analyzing this and fitting observed cross-country patterns is the second main contribution of this paper. While the assumptions made here on the use of technology are admittedly much simpler than those in the micro literature, they make it possible to transparently obtain a full set of general equilibrium results and compare these to the evidence.

The calibration exercise in Section 5 shows that the model fits the U.S. experience, including the history of average firm size, well. Although not targeted in the calibration, it also generates a trend in income concentration at the top very similar to that documented by Piketty and Saez (2006). More strikingly, using parameter values from the calibration to the U.S., the model matches not only the qualitative relationship between per capita income and the entrepreneurship rate, the fraction of small firms, average firm size, and firm size dispersion and skewness across countries, but actually delivers a good quantitative fit for most of these dimensions. In particular, the predicted changes in the entrepreneurship rate, in the fraction of small firms and in average firm size with per capita income are very close to those in the data. Because of its stylized nature, the model overpredicts the sensitivity of firm size dispersion and skewness to per capita income in the lower half of the cross-country income distribution. In the upper half of the income distribution, however, these variables also fit the data very well.

The simple model with skill-biased change in entrepreneurial technology proposed here hence fits cross-country patterns in the firm size distribution very well. It can thus provide a baseline when thinking about differences in the firm size distribution across countries. In addition, it provides a convenient way of taking some results from the micro literature on

\footnotetext{
for entrepreneurs.

${ }^{7}$ Important references include Garicano (2000), Gabaix and Landier (2008) and Terviö (2008). For a survey of the CEO literature see Bertrand (2009). Terviö (2008) relates high CEO pay to firm size, and Gabaix and Landier (2008) attribute recent increases in CEO pay to the increase in size of U.S. companies. Kaplan and Rauh (2013) conjecture that "Although the two papers do not seek to explain why firms (and funds) have been able to become so much larger over time, the same technological change that is biased towards skills may have helped firms and funds to become larger during our sample period." The present paper takes exactly that step.

${ }^{8}$ An exception is Roys and Seshadri (2013), who study occupational choice and human capital acquisition among workers and managers with a focus on sorting. While their model is highly interesting and generates several patterns that are consistent with the data, some of its predictions fit less well with the facts documented here, in particular size dispersion across countries.
} 
entrepreneurs and skills to macroeconomics. (Section 5.4 discusses some alternative potential explanations; they cannot fit all the patterns in the data documented in Section 2.)

Besides the references above, this paper is related to two further strands of literature. First, several papers have analyzed entrepreneurial choice and its macroeconomic implications; see Quadrini (2009) for an excellent review. An important paper here is Cagetti and De Nardi (2006). These authors fit a model of entrepreneurial choice to U.S. data with the aim of assessing the contribution of entrepreneurship and credit constraints to wealth inequality. Like other contributions to this literature, their model does not involve changes in entrepreneurial choice with development. Entrepreneurial choice and development has been analyzed by Banerjee and Newman (1993), Lloyd-Ellis and Bernhardt (2000) and Akyol and Athreya (2009). The first two of these papers focus on the role of the wealth distribution when there are credit constraints. The latter in addition takes into account how the outside option of employment varies with per capita income, and how this affects entrepreneurial choice. None of them features an evolving role for skills as the present paper does.

Secondly, some papers have taken a similar view of skills, complexity or the role of the entrepreneur as this paper. Teulings (1995) relates skills to the ability to deal with complexity, but does not consider entrepreneurship. Lloyd-Ellis (1999) assumes that skill is required for implementing a technology, but focusses on the tradeoff between using skills for R\&D or for implementation. Jovanovic and Rousseau (2008) also model a manager's task as finding the right combination of heterogeneous inputs but focus on the quality of the match between a firm's products and its workers' skills, not on the evolution of entrepreneurial choice and the firm size distribution with development. Grossman, Helpman and Kircher (2013) analyze matching among heterogeneous managers and workers under complementarity in a model of trade, but do not allow for occupational choice and do not explore consequences for the firm size distribution.

The paper is organized as follows. Section 2 describes the data and documents relevant facts about entrepreneurship and the firm size distribution. Section 3 presents the model, and Section 4 shows how entrepreneurship and characteristics of the firm size distribution change with development. Finally, Section 5 presents a generalization of the model and quantitative results, and Section 6 concludes. 


\section{Entrepreneurship, the firm size distribution and de- velopment}

In this section, I show facts on the firm size distribution across countries using two complementary data sets. Obtaining data on the firm size distribution across countries is notoriously hard because measurement in national surveys or administrative data is not harmonized across countries. The Global Entrepreneurship Monitor (GEM) and Amadeus constitute two exceptions. ${ }^{9}$ To the best of my knowledge, this is the first paper using GEM data across countries for macroeconomic analysis, and one of the first to use Amadeus for this purpose. The GEM is particularly useful for capturing the lower tail of the firm size distribution (below, defined as < 300 employees) in a harmonized way across countries. For information on the upper tail (>300 employees) I use the Amadeus data base collected by Bureau Van Dijk. I briefly present the two datasets in the next subsection.

The remainder of the section then shows six facts on occupational choice and the firm size distribution across countries obtained using the two data sets: entrepreneurship, the self-employment rate and the importance of small firms all fall with per capita income, while the mean, median, percentiles above the median, standard deviation and skewness of the firm size distribution all increase with per capita income. The first three facts are known yet worth revisiting briefly, while the last three are new, and shed new light on the first three.

\subsection{Data sources}

\subsubsection{The Global Entrepreneurship Monitor (GEM) survey}

The GEM is an individual-level survey run by London Business School and Babson College now conducted in more than 50 countries. Country coverage has been expanding since its inception in 1999, with data for several years available for most countries. The micro data is in the public domain, downloadable at http://www.gemconsortium.org/. Most developed economies are represented, plus a substantial number of transition and developing economies, ensuring that the data covers a wide variety of income levels. ${ }^{10}$

The survey focusses on entrepreneurship. That is, while the survey overall is conducted by local research organizations or market research firms to be representative of a coun-

\footnotetext{
${ }^{9}$ Another exception are some OECD publications such as Bartelsman, Haltiwanger and Scarpetta (2004) that provide information on some OECD countries and a limited number of other countries. Their numbers arise from an effort to harmonize national official data, while in the case of the GEM and Amadeus, data collection is already harmonized.

${ }^{10}$ Inclusion in the survey depends on an organization within a country expressing interesting and financing data collection.
} 
try's population, it contains only limited demographic information (e.g. education) on nonentrepreneurs. It contains much richer information on entrepreneurs, including their firm's employment.

Importantly, the survey is designed to obtain harmonized data across countries. It is thus built to allow cross-country comparisons, the purpose for which it is used here. In addition, because it is an individual-level survey, it captures all types of firms and not just firms in the formal sector or above some size threshold. For studying occupational choice, this is evidently important. This feature makes the GEM data an essential source of information for the purposes of the analysis in this paper. Its coverage of small firms is unrivalled compared to firm- or establishment-level surveys such as the World Bank Group Entrepreneurship Survey, which covers only registered corporations. Moreover, Reynolds et al. (2005), Acs, Desai and Klapper (2008) and Ardagna and Lusardi (2009) have shown that observations from GEM data tend to align well with those based on other sources.

To obtain data on entrepreneurship rates, I use country averages of the country-level data covering the years 2002-2008 available on the GEM website for 66 countries. Micro data is available for 1999 to 2005 and covers fewer countries. I use it to obtain statistics on the firm size distribution, for which no country-level numbers are reported. As the initial years of the survey may be less reliable, I use the micro data for the period 2001-2005. For this period, data is available for 47 countries, though not for all years for all countries. Pooling the available years for each country, the number of observations per country is between 2,000 in some developing economies and almost 80,000 in the UK, with a cross-country average of 11,700 . This is sufficient for computing the summary statistics of the firm size distribution that I use in the following. Unfortunately, in many countries, there are not enough observations for obtaining reliable estimates for more detailed size classes, so I rely on summary statistics for the entire distribution. ${ }^{11}$

I consider someone an entrepreneur if they declare running a firm that they own and they have already paid wages (possibly to themselves, for the self-employed). I then obtain firm size data for these firms, truncating the distribution at 300 employees to avoid overlap with the Amadeus data.

The GEM dataset is very useful because of the harmonized data collection and its unrivalled coverage of small firms. Yet, because the GEM is a household survey, publicly listed firms with dispersed ownership are not included. These are particularly important in highincome countries and tend to be large. Other large firms may also be undersampled. I therefore complement the information from GEM with information from Amadeus.

\footnotetext{
${ }^{11}$ I use data for all countries except for Latvia, for which average employment is $60 \%$ above the next-highest value. I thus exclude it from the parts of the analysis involving size.
} 


\subsubsection{Amadeus}

This database contains financial and employment information on more than five million companies from 34 European countries, including all of the European Union. The data is collected by the company Bureau Van Dijk (BvD). BvD and its local subsidiaries collect data on public and private companies, which under European regulations typically are required to file some financial information in publicly accessible local registers. The information in Amadeus thus stems from companies' official filed and audited accounts, with the exception of data for some Eastern European countries, which is collected from the companies themselves. The Amadeus database has been used for firm level analysis by Bloom et al. (2012), among others.

The current issue of Amadeus contains information on the years 2006 to 2011, with more limited information on 2012 available, too. It covers all sectors, except for banks and insurance companies. In Western Europe, according to information provided by BvD, firms with at least 300 employees are typically required to publicly file their accounts. The threshold can be lower in some countries, and can also depend on a firm's legal status. Companies with a legal status conferring limited liability typically are required to file. Since larger companies tend to have such a legal status, the database features excellent coverage of firms with at least 300 employees in all countries, making reliable cross-country comparisons possible.

In the following, I use Amadeus data on firms with at least 300 employees from countries where total employment in the database corresponds to at least $10 \%$ of private sector employment in the country. I use data for 2007, to exclude the effect of the deep global recession in the following years. ${ }^{12}$

The combination of data from the GEM and Amadeus surveys allows describing patterns in the firm size distribution across countries with unprecedented breadth. Both data sets cover a number of countries that is substantially larger than that used in previous studies. Each survey affords deep insights into one of two parts of the firm size distribution. Combining these insights makes it possible to make statements about the entire distribution.

Next, I will present facts on the firm size distribution for both small and medium sized

\footnotetext{
${ }^{12}$ Private sector employment is computed as total employment from the World Development Indicators minus general government employment, from the same source. Qualitative results are not sensitive to using different coverage cutoffs, like 0.33 or 0.5 , though of course significance of results suffers from dropping data. Results are also similar when all years are used. The countries included in the analysis below are Austria, Belgium, Belorussia, Bosnia and Herzegovina, Bulgaria, Croatia, the Czech Republic, Estonia, Finland, France, Germany, Great Britain, Greece, Hungary, Iceland, Ireland, Italy, Latvia, Lithuania, Luxembourg, Malta, Montenegro, the Netherlands, Poland, Portugal, Romania, Russia, Serbia, the Slovak Republic, Slovenia, Spain, Sweden, Switzerland, and Ukraine.
} 
firms, drawing on the GEM dataset, and for large firms, drawing on Amadeus, where "large" is defined as at least 300 employees. Related evidence from the literature will be discussed concurrently.

\subsection{The facts}

To establish six facts on the firm size distribution and per capita income, Figures 1 to 7 contain plots of statistics on entrepreneurship and the firm size distribution against sameyear real GDP per capita at purchasing power parity from the Penn World Tables (Summers and Heston 1991, Heston, Summers and Aten 2009). ${ }^{13}$ Results are generally similar whether using the level or log of GDP per capita. The figures in each case show the more readable version. Each figure also contains an OLS line of best fit. Table 1 reports bivariate regression results for the log of GDP per capita. The regression lines drawn in the figures are all significant at least at the $5 \%$ level except for two lines in each panel of Figure 5. Measures of fit are also reported in Table 1 and are high for a bivariate relationship in cross-sectional data. Table 6 in the Appendix shows that results are similar when industry dummies are included in the regression; the cross-country patterns thus are not driven by systematic differences in industry composition.

Fact 1 The entrepreneurship rate falls with income per capita (see Figure 1).

This fits with the finding of Gollin (2007) that the self-employment rate falls with income per capita in ILO data. ${ }^{14}$ Although the negative relationship between the entrepreneurship rate and per capita income is very robust, it does not seem to be well known. The reason for that is that the population of entrepreneurs under consideration matters. The fact holds for broad measures of entrepreneurship that include small firms. Because the share of small firms is larger in poorer countries (see also the next fact), the relationship is reversed when considering only large firms or using sample selection criteria that exclude most small firms, like incorporation. This is the case for instance in data from the World Bank Group Entrepreneurship Survey, which covers only registered corporations. The positive relationship found there is often attributed to differences in regulation; see e.g. Klapper, Laeven and Rajan (2006) and Barseghyan (2008). For studying occupational choice, focussing on registered

\footnotetext{
${ }^{13}$ By its sampling procedure, the GEM captures few agricultural businesses (only $4 \%$ on average). As self-employment is typically higher and income per capita typically lower in agriculture (see e.g. Caselli 2005, Restuccia, Yang and Zhu 2008), the facts obtained using the GEM would be even more pronounced if they could be produced using a reliable up-to-date measure of non-agricultural GDP per capita at PPP.

${ }^{14}$ In U.S. history, the self-employment rate fell continuously until the mid-1970s, when it temporarily rebounded for a few years, mainly due to changes in tax rates (Blau 1987; see also Hipple 2004).
} 


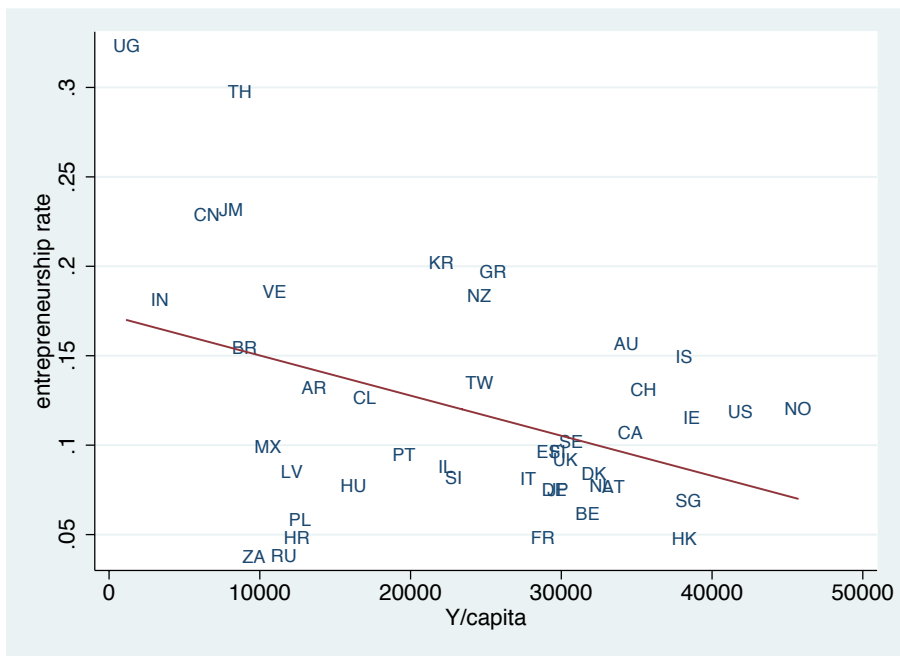

Figure 1: The entrepreneurship rate and per capita income.

Notes: Real GPD per capita for 2005 at purchasing power parity from the Penn World Tables (Summers and Heston 1991, Heston et al. 2009); entrepreneurship rate from GEM data, http://www.gemconsortium.org. Entrepreneurs are defined as survey respondents who declare running a firm that they own and who have already paid wages, possibly to themselves. Regression results underlying the OLS line of best fit plotted in the figure are reported in Table 1.

firms is not sufficient and it is necessary to take into account all firms, as in the GEM or ILO data.

Fact 2 Large firms are more prevalent and account for a larger fraction of employment in richer countries (see Figure 2).

Again, while this fact is not new, ${ }^{15}$ it is useful to see that it is strongly reproduced in both GEM and Amadeus data. GEM data clearly reveal that firms with more than 10 employees (which make up a relatively small fraction of firms in most countries!) are much more frequent in richer countries. Similarly, large firms (at least 300 employees) account for a large fraction of employment in rich countries, but a much smaller one in poor economies. ${ }^{16}$

This fact is important not only in its own right. Most moments of the size distribution can be expressed as a weighted sum of moments of parts of the distribution. The GEM and Amadeus data each provide information on moments of one part of the size distribution.

\footnotetext{
${ }^{15}$ Beck et al. (2004) show that sales of the top 100 manufacturing firms as a fraction of GDP are larger in richer economies.

${ }^{16}$ The share of small firms also falls over the whole sample period 1977-2009 in the U.S. Census BDS data presented below. The same pattern holds for Thailand over the period 1987 to 1996; see Wiboonchutikula (2002).
} 


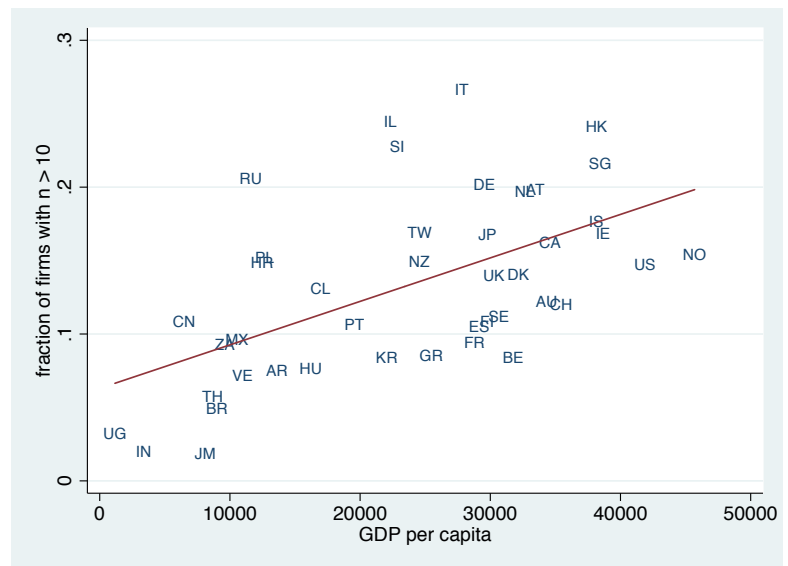

(a) The fraction of firms with $n>10$ (GEM)

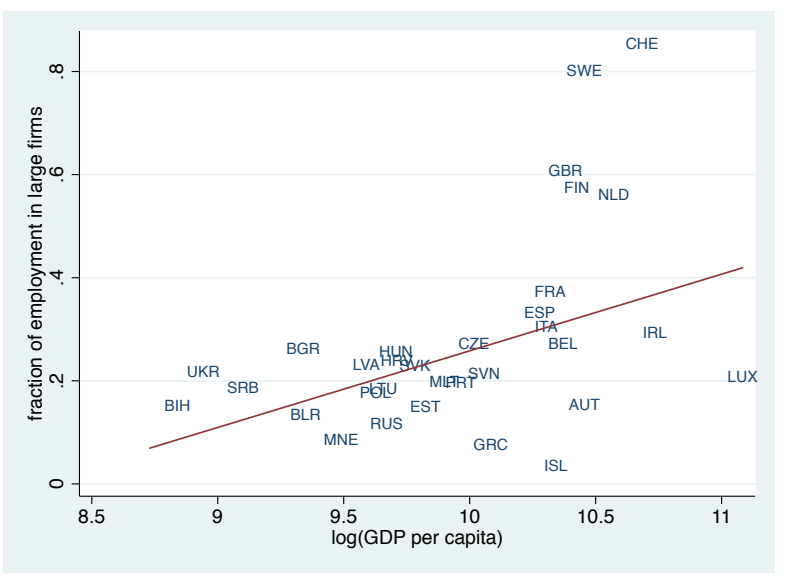

(b) The fraction of employment in large firms $(n \geq$ 300) (Amadeus)

Figure 2: The importance of large firms and per capita income.

Notes: Real GPD per capita for 2005 at purchasing power parity from the Penn World Tables (Summers and Heston 1991, Heston et al. 2009); employment data from the GEM, http://www.gemconsortium.org, for the left panel and from Amadeus for the right panel. Panel (b) shows total employment in firms with at least 300 employees in Amadeus over private sector employment, computed as total employment minus general government employment from the World Development Indicators. (Results are very similar when not adjusting for government employment.) Regression results underlying the OLS line of best fit plotted in the figure are reported in Table 1.

Fact 2 establishes how weights on each part of the distribution vary with per capita income and therefore allows making statements about the entire distribution.

Fact 3 Average firm employment increases with income per capita (see Figure 3).

It is clear that average firm employment is larger in richer countries in both samples. Since the average for the entire economy is a weighted average of the averages for the two parts of the distribution, and the weight of large firms increases with income per capita (see Fact 2), the relationship in the two subsamples extends to the entire distribution.

This fact is of course closely related to Fact 1, as high entrepreneurship rates must necessarily imply smaller average employment. ${ }^{17}$ Previously, this relationship has only been documented across a limited number of countries (Tybout 2000). In addition, Lucas (1978) reported that average firm size increased with per capita income over U.S. history (1900-70). Figure 4 shows that this time-series relationship persists. It reports measures of average firm size close to those used by Lucas (the two series labelled "BEA Survey of Current Business" and "Dun \& Bradstreet", both from Carter, Gartner, Haines, Olmstead, Sutch and

\footnotetext{
${ }^{17}$ Strangely enough, this simple relationship often seems to escape policy discussions on promoting entrepreneurship.
} 


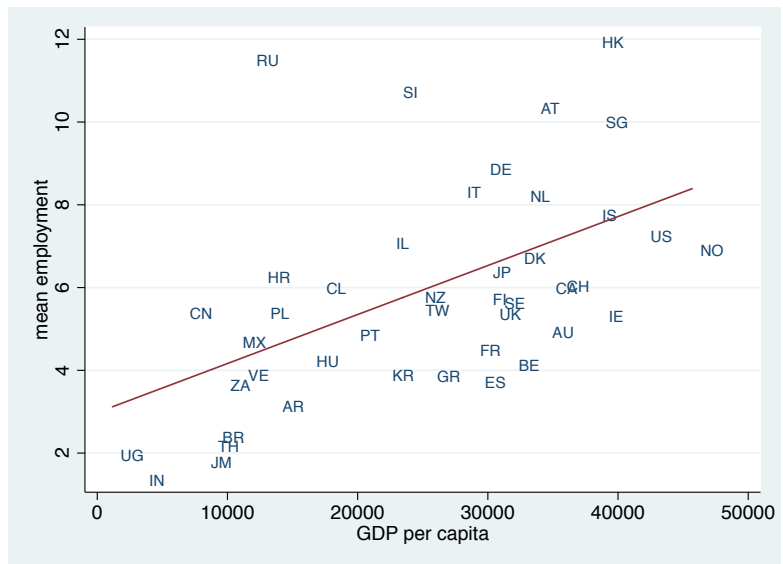

(a) Small and medium sized firms (GEM, $n<300)$

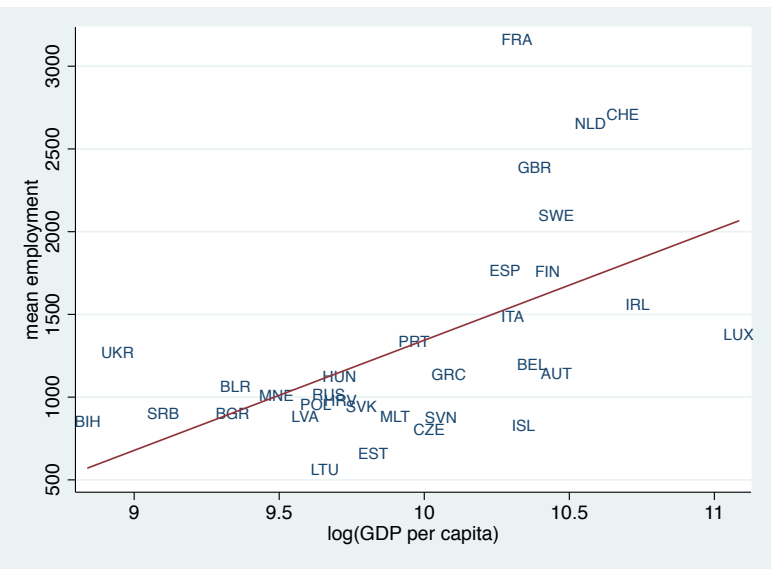

(b) Large firms (Amadeus, $n \geq 300$ )

Figure 3: Average employment and per capita income.

Notes: Data sources as in Figure 2. Regression results underlying the OLS line of best fit plotted in the figure are reported in Table 1.

Wright 2006) and more recent data. The most recent available series is from U.S. Census Business Dynamics Statistics (BDS). This is aggregated annual data based on the Longitudinal Business Database (LBD) maintained by the Census Bureau's Center for Economic Studies which draws on, among other sources, the Business Register, Economic Censuses and IRS payroll tax records. As a result, the BDS covers employer firms accounting for $98 \%$ of U.S. private employment. In order to obtain average firm size for a broader measure of firms I also report average firm size when taking into account non-employer firms, or selfemployed without employees. This measure is obtained by combining BDS data with data on unincorporated self-employed businesses reported in Hipple (2010). ${ }^{18}$ While the five series shown in the figure cover slightly different populations of firms, they all show an increasing trend, except for the interwar period. This upward trend of course occurs simultaneously with increasing per capita income. Firm size thus increases with per capita income both in U.S. history and across countries.

Jovanovic and Rousseau (2008) show that another measure of size, patents or trademarks per firm, has also increased from 1971 to 2006 (see also footnote 3). For other countries, some information can be gathered from separate sources. A special issue of Small Business Economics reveals that average firm size also increased with development in several East Asian economies. This is the case in Indonesia (Berry, Rodriguez and

\footnotetext{
${ }^{18}$ Unfortunately, this series is rather short. This is because information on employment by the unincorporated self-employed is only available starting in 1995. Many thanks to Steven Hipple for providing some additional information.
} 


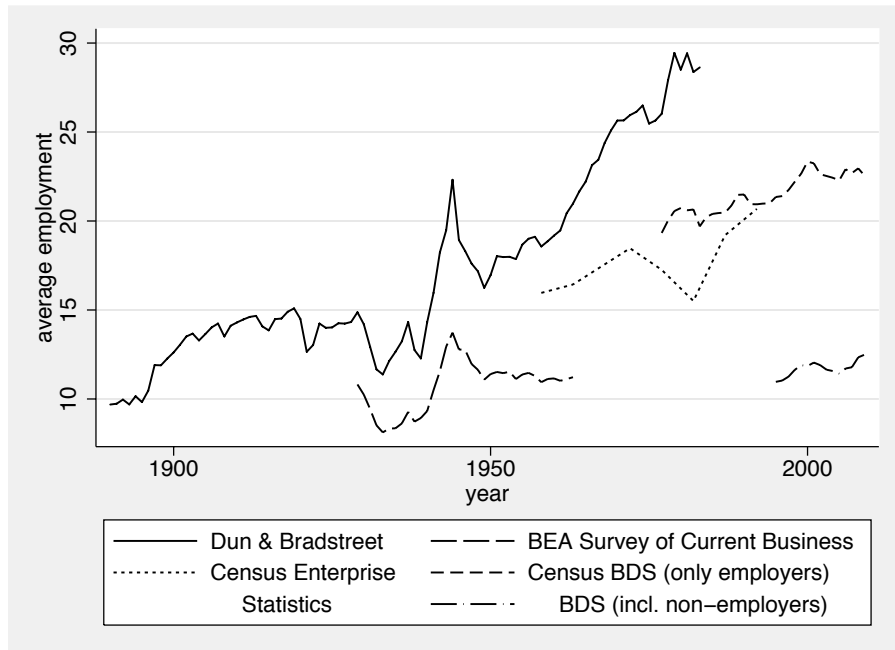

Figure 4: Average firm size (employment) over U.S. history, 1890-2006

Sources: Census Bureau Business Dynamics Statistics (BDS): data available at http://www.ces.census . gov/index.php/bds; when including non-employers, combined with Current Population Survey (CPS) data reported in Hipple (2010); Census Enterprise Statistics series: from various Census reports; BEA Survey of Current Business series: from Carter et al. (2006, Series Ch265); Dun \& Bradstreet series: from Carter et al. (2006, Series Ch408). The first three sources also report total employment. For the last two series, employment is from Carter et al. (2006, Series Ba471-473 and Ba477). The Dun \& Bradstreet firm counts exclude finance, railroads and amusements. Adjusting employment for this using Series Ba662, Dh31, Dh35, Dh53 and Df 1002 shortens the series without affecting the trend. Starting 1984, Dun \& Bradstreet gradually cover additional sectors, at the cost of comparability over time, so I only plot data up to 1983. Series Ch1 in Carter et al. (2006), which draws on Internal Revenue Service data, also contains historical firm counts but is less useful because of frequent changes of definition, in particular for proprietorships.

Sandee 2002), Japan (Urata and Kawai 2002), South Korea (Nugent and Yhee 2002) and Thailand (Wiboonchutikula 2002). Only in Taiwan, the smallest of these countries, did it fall (Aw 2002). Tomlin and Fung (2012) report that average firm size in Canada increased between 1988 and 1997. Felbermayr, Impullitti and Prat (2013, Table 4) show the same for Germany between 1996 and 2007. For large firms only, Beck et al. (2004) show that assets of the largest 100 manufacturing firms are larger in richer economies. The upward trend in average firm size thus has occurred in a substantial number of countries.

Fact 4 The median and higher percentiles of the firm size distribution increase with income per capita (see Figure 5).

This is the fact for which the use of micro data is most important, as it seems impossible to obtain from other sources in a consistent way for more than a small number of countries. Figure 5 is a key piece of evidence. It shows that both the distribution of small firms and that of large ones change with income per capita. While small firms exist in all countries, 


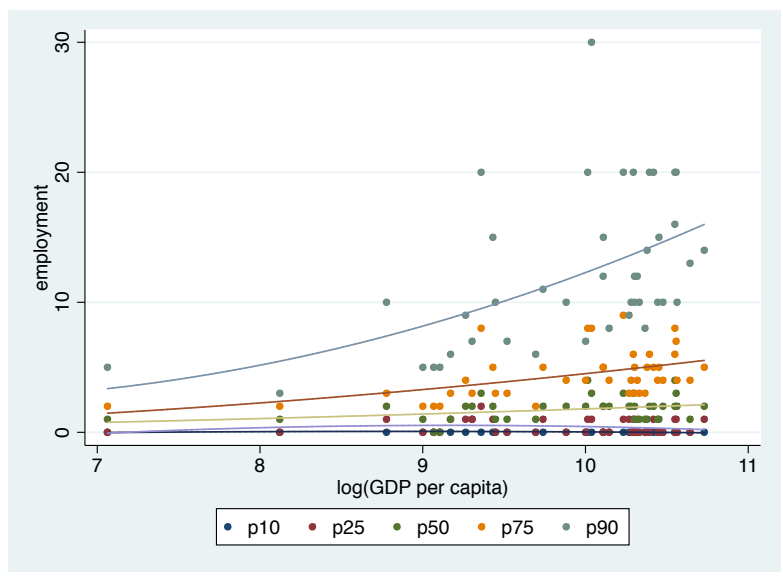

(a) Small and medium sized firms (GEM, $n<300)$

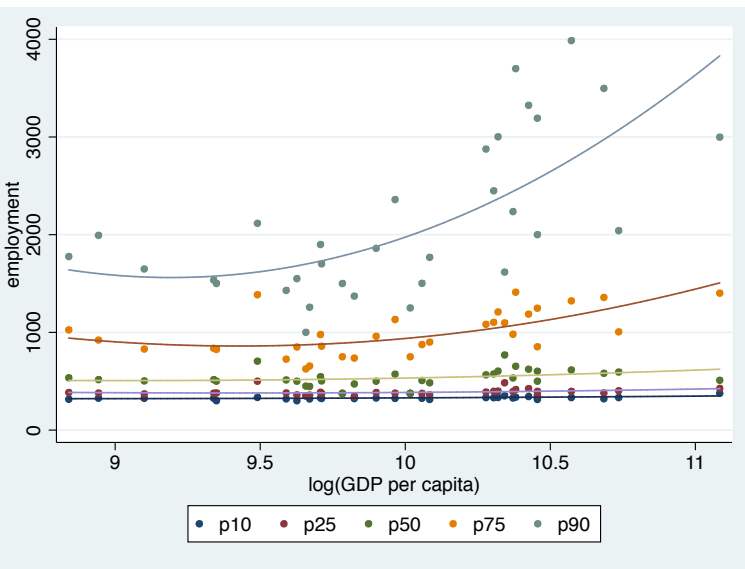

(b) Large firms (Amadeus, $n \geq 300$ )

Figure 5: The firm size distribution and per capita income.

Notes: Data sources as in Figure 2. The figure shows employment at the 10th, 25th, 50th, 75th and 90th percentile of each country's firm size distribution. The lines are quadratic fits of log output per capita against each percentile. Coefficients from a linear regression of size percentiles on output per capita are reported in Table 1. Results are similar when the level of GDP per capita is used instead of the log.

and low percentiles of the partial size distributions do not change much with income per capita, percentiles from the median up change substantially. Regression results reported in Table 1 below show that these patterns are statistically strongly significant. Moreover, the regression coefficients on income per capita are significantly larger for high percentiles of the distribution compared to lower ones, with the exception of the comparison of the 10th and 25th percentiles.

Fact 2 - the share of large firms grows with income per capita - allows making statements about the entire distribution. Firms with more than 300 employees constitute a small fraction of firms everywhere, but a relatively larger one in richer economies. As a consequence, firms with 300 employees, the dividing line between the two panels of Figure 5, are situated in higher percentiles of the size distribution in poor countries compared to rich countries. The same carries over to percentiles of the distribution of firms with less than 300 firms. This implies that firms at e.g. the 90th percentile of the size distribution of small and medium sized firms are larger in richer countries, as seen in panel (a), although they are at a lower percentile in the overall size distribution in those countries. The size of firms at a similar intermediate percentile of the entire size distribution thus increase with income per capita more strongly than visible in the figure. Similarly, firms at high percentiles of the distribution of large firms are larger in richer countries, although they are located at lower percentiles of the overall distribution. Firms at similar, fixed percentiles must again be larger in richer 
economies. Finally, the 10th or 25th percentile of the distribution of firms with at least 300 employees correspond to lower percentiles of the entire distribution in relatively richer countries, despite similar size of firms there. Again, this implies that the size of firms at a given percentile must increase with per capita income in the middle of the distribution. Only at the bottom of the size distribution does firm size appear not to change with per capita income.

Figure 5 also shows how higher moments of the firm size distribution change with income per capita. The following two facts make this explicit.

Fact 5 The dispersion of firm size in terms of employment increases with income per capita (see Figure 6).

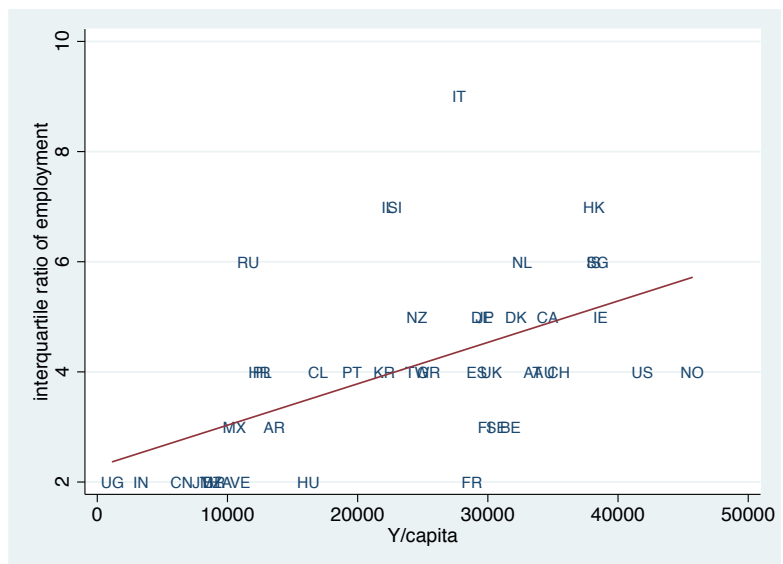

(a) Small and medium sized firms (GEM, $n<300)$

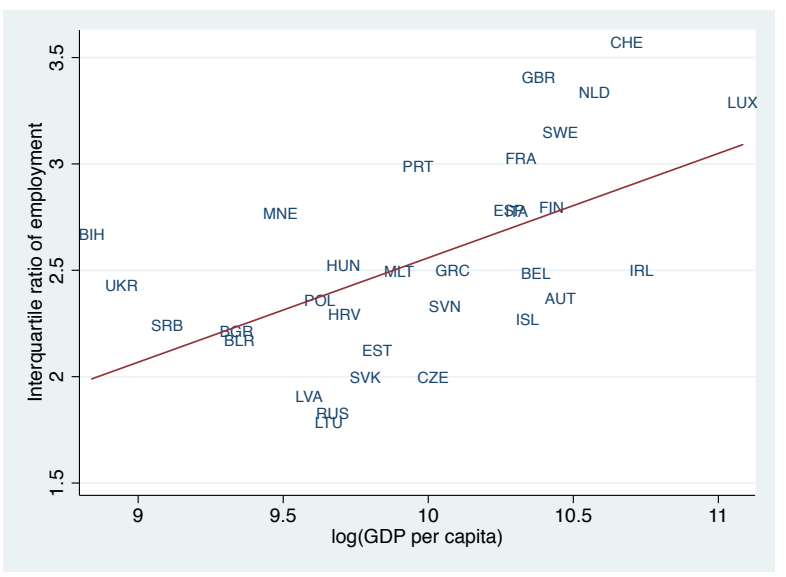

(b) Large firms (Amadeus, $n \geq 300$ )

Figure 6: Interquartile ratio of employment and per capita income.

Notes: Data sources as in Figure 2. Denoting the $x^{\text {th }}$ percentile of the firm size distribution by $p_{x}$, the interquartile ratio is $p_{75} / p_{25}$. Regression results underlying the OLS line of best fit plotted in the figure are reported in Table 1.

The figure shows a clear positive relationship between the interquartile ratio of firm size and per capita income. While the interquartile ratio is a useful measure in this context due to its robustness to outliers, the relationship is very similar when plotting the standard deviation of firm size against per capita income (see Figure 13 in the Appendix). The increasing weight of large firms again implies that the relationship translates from parts of the distribution to the entire distribution.

The only previous mention of such a relationship I could find is Bartelsman et al. (2004), who show that firm size dispersion is substantially higher in industrialized countries compared to emerging markets, using OECD and World Bank data for a much smaller set of 
countries. In the time series, Kehrig (2012) shows using data from the Annual Survey of Manufactures that total factor productivity dispersion has increased over time in the United States, with its standard deviation increasing by $80 \%$ between 1972 and 2010. Faggio, Salvanes and Van Reenen (2010) show the same pattern for the United Kingdom, and Felbermayr et al. (2013) for Germany. In line with both this and the previous fact, Elsby, Hobijn and Şahin (2013) show that there have been large increases in income inequality among proprietors, driven mainly by increases at the top. ${ }^{19}$

The finding of varying dispersion is important, because it indicates that larger average size in richer countries is not simply due to a shift to the right of the firm size distribution. Finally,

Fact 6 The skewness of firm size in terms of employment increases with income per capita (see Figure 7).

The figure shows that skewness, again measured in a way that is robust to outliers, strongly increases with per capita income, implying increasing importance of the right tail of large firms. This pattern also arises when using an alternative measure of skewness; see Figure 14 and Table 5 in the Appendix.

Overall, richer countries thus feature fewer, larger firms, with a firm size distribution that is more dispersed and more skewed. As Figure 5 makes clear, the change in moments of the size distribution with income per capita thus is not simply due to a shift or a meanpreserving spread of the size distribution, but rather to the size distribution stretching out further to the right.

The first three facts have received some previous attention. Lucas (1978) in his seminal occupational choice framework explains Fact 3 by allowing for complementarity in production between the capital and labor inputs. More productive economies accumulate more

\footnotetext{
${ }^{19}$ Hsieh and Klenow (2009) compute TFP dispersion in China, India and the U.S.. Apart from the fact that their numbers are hard to compare to the ones obtained here because they are restricted to manufacturing and refer to establishments, not firms, they are also effectively forced to impose a minimum size cutoff because some variables are missing for small establishments in their otherwise very rich data. This affects measured dispersion. Comparing their Table I to Census BDS data shows that in the case of the U.S. in 2001 for instance, they need to exclude almost half of all manufacturing establishments. The size distribution plotted in their Figure IX shows that these are mostly small establishments belonging to firms with less than 10 employees. This is similar for India. Using data on the entire plant size distribution in Indian manufacturing, García-Santana and Pijoan-Mas (2012) show that there is a very large number of very small plants: $95 \%$ of plants have 5 or fewer employees, average plant size is 2.6, and size dispersion very limited. While these issues are less important for the purpose of Hsieh and Klenow's (2009) paper, it is preferable to have firm data without a size cutoff and without the limitation to a single sector for analyzing occupational choice between wage work and entrepreneurship.
} 


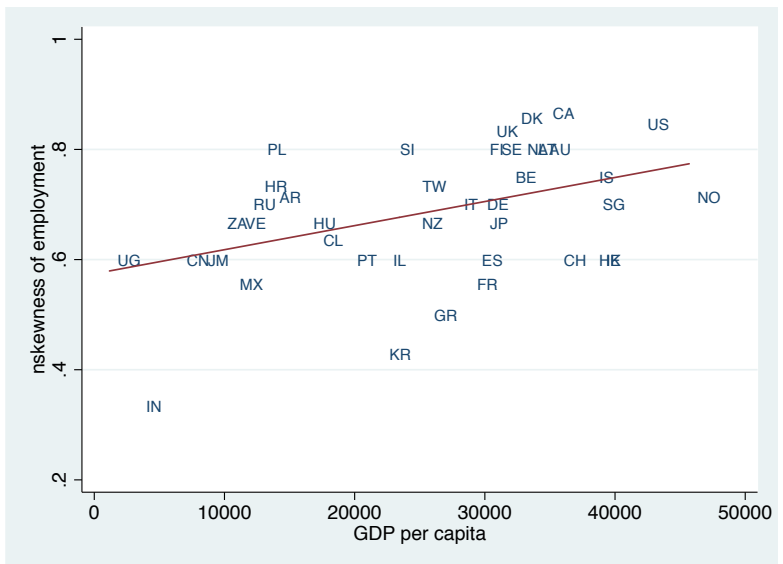

(a) Small and medium sized firms (GEM, $n<300)$

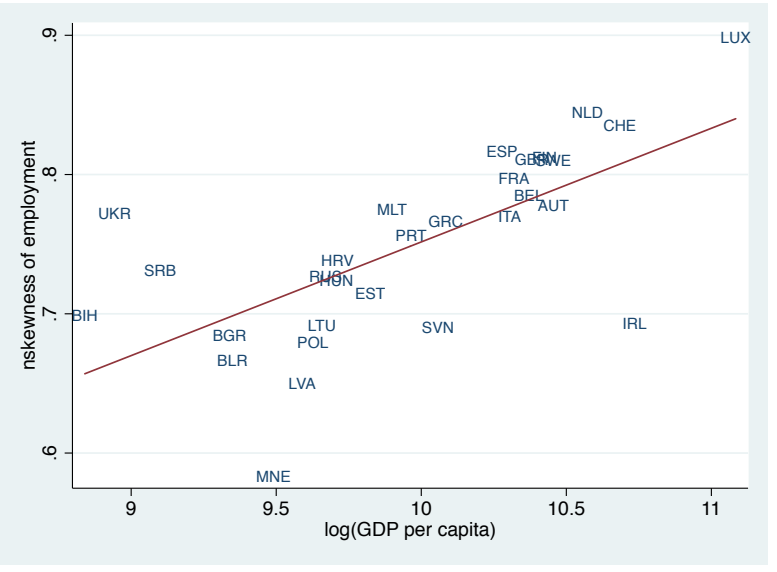

(b) Large firms (Amadeus, $n \geq 300$ )

Figure 7: "nskewness" and per capita income.

Notes: Data sources as in Figure 3. Denoting the $x^{\text {th }}$ percentile of the firm size distribution by $p_{x}$, the "nskewness" or $90 / 10$ percentile skewness measure used here is $\left(\left(p_{90}-p_{50}\right)-\left(p_{50}-p_{10}\right)\right) /\left(p_{90}-p_{10}\right)$. Regression results underlying the OLS line of best fit plotted in the figure are reported in Table 1. Panel (a) excludes Brazil and Thailand, where $p_{50}=p_{10}$, implying nskewness of 1 . Panel (b) excludes Iceland, which has very low nskewness, and the Czech and Slovak Republics, where $p_{50}=p_{10}$, implying nskewness of 1 .

capital, which with the complementarity raises wages more than profits, reducing the share of entrepreneurs and thus raising the average size of firms. Gollin (2007) explicitly introduces self-employment as an option and then uses a similar framework to fit self-employment rates across countries (Fact 1).

In each of these cases, the agents who choose entrepreneurship are the fraction of the population that is best at it. Increases in productivity raise the entry threshold and reduce that fraction. While this implies that in richer countries, there are fewer and larger firms, this mechanism does not explain Facts 4 through 6. To the contrary, a more homogeneous population of entrepreneurs may well reduce the standard deviation and skewness of firm size. Other potential explanations for differences in average firm size are briefly discussed in Section 5.4. They also have problems matching the patterns in dispersion and skewness. Facts 4 through 6 are thus important for evaluating different models that can fit Facts 1 and 3. The model developed in the next section addresses these points and thus is able to explain all six facts.

\section{A simple model}

The economy consists of a unit continuum of agents and an endogenous measure of firms. Agents differ in their endowment of effective units of labor $a \in[0, \bar{a}]$ that they can rent to 
Table 1: The firm size distribution and per capita income.

\begin{tabular}{|c|c|c|c|c|c|c|}
\hline \multirow[b]{2}{*}{ Moment (Fact/Figure) } & \multicolumn{3}{|c|}{ GEM data $(n<300)$} & \multicolumn{3}{|c|}{ Amadeus data $(n \geq 300)$} \\
\hline & Coeff. & $\mathrm{SE}$ & $\mathrm{R}^{2}$ & Coeff. & $\mathrm{SE}$ & $\mathrm{R}^{2}$ \\
\hline Entrepreneurship rate $(1 / 1)$ & $-0.048^{* * *}$ & $(0.012)$ & 0.291 & & & \\
\hline Fraction of firms with $n>10$ (2/2) & $0.049^{* * *}$ & $(0.010)$ & 0.352 & & & \\
\hline $\begin{array}{l}\text { Fraction of employment } \\
\quad \text { in firms with } n \geq 300\end{array}$ & & & & $0.176^{* * *}$ & $(0.058)$ & 0.233 \\
\hline Average employment (3/3-4) & $1.893^{* * *}$ & $(0.454)$ & 0.298 & $665.6^{* * *}$ & $(180.8)$ & 0.311 \\
\hline $\begin{array}{l}\text { Interquartile ratio } \\
\text { of employment }(5 / 6)\end{array}$ & $2.096^{* *}$ & $(0.735)$ & 0.368 & $0.491^{* * *}$ & $(0.133)$ & 0.313 \\
\hline $\begin{array}{l}\text { nskewness of employment } \\
\text { average size }\left(6 /{ }^{\prime}\right)\end{array}$ & $0.070^{* * *}$ & $(0.023)$ & 0.195 & $0.082^{* * *}$ & $(0.017)$ & 0.451 \\
\hline \multicolumn{7}{|l|}{ Employment distribution $(4 / 5)$ : } \\
\hline$p_{10}$ & -0.025 & $(0.032)$ & 0.015 & $12.0^{* *}$ & $(5.8)$ & 0.125 \\
\hline$p_{25}$ & -0.026 & $(0.114)$ & 0.001 & 16.0 & $(10.8)$ & 0.068 \\
\hline$p_{50}$ & $0.385^{* *}$ & $(0.179)$ & 0.102 & $48.9^{*}$ & $(26.7)$ & 0.101 \\
\hline$p_{75}$ & $1.180^{* * *}$ & $(0.344)$ & 0.222 & $230.5^{* * *}$ & $(64.9)$ & 0.296 \\
\hline$p_{90}$ & $3.861^{* * *}$ & $(1.055)$ & 0.246 & $918.5^{* * *}$ & $(210.3)$ & 0.389 \\
\hline Test that... & p-value & & & p-value & & \\
\hline coefficients equal at all $p_{i}$ & 0.000 & & & 0.001 & & \\
\hline$b\left(p_{25}\right)>b\left(p_{10}\right)$ & 0.995 & & & 0.627 & & \\
\hline$b\left(p_{50}\right)>b\left(p_{25}\right)$ & 0.003 & & & 0.060 & & \\
\hline$b\left(p_{75}\right)>b\left(p_{50}\right)$ & 0.000 & & & 0.002 & & \\
\hline$b\left(p_{90}\right)>b\left(p_{75}\right)$ & 0.000 & & & 0.000 & & \\
\hline
\end{tabular}

Notes: Data sources as in Figure 2. The table shows coefficients from bivariate regressions of each moment on $\log$ GDP per capita, the standard errors on those coefficients, and the $\mathrm{R}^{2}$ for each regression. A constant is also included in each regression (coefficient not reported). $p_{i}$ stands for the $i^{\text {th }}$ percentile of the employment distribution. $b\left(p_{i}\right)$ refers to the coefficient on log GDP per capita in the regression of $p_{i}$ on $\log$ GDP per capita. "nskewness" or 90/10 percentile skewness is defined as $\left(\left(p_{90}-p_{50}\right)-\left(p_{50}-p_{10}\right)\right) /\left(p_{90}-p_{10}\right)$. ${ }^{* * *}$ $\left({ }^{* *}\right)\left[{ }^{*}\right]$ denotes statistical significance at the $1 \%(5 \%)[10 \%]$ level.

firms in a competitive labor market. Refer to this endowment as "ability". Differences in ability can be thought of as skill differences. They are observable, and the distribution of ability in the population can be described by a $p d f \phi(a)$.

Agents value consumption $c$ of a homogeneous good, which is also used as the numéraire. They choose between work and entrepreneurship to maximize consumption. ${ }^{20}$ The outcome

\footnotetext{
${ }^{20}$ Concave utility would not affect qualitative results. While in general, risk aversion is an important factor affecting entrepreneurial entry (see e.g. Kihlstrom and Laffont 1979, Vereshchagina and Hopenhayn 2009), the mechanism at the heart of this paper does not interact with it. An extension in Section 5 can be
} 
of this choice endogenously determines the measures of workers and of firms in the economy.

Labor supply and wage income. Consumption maximization implies that individuals who choose to be workers supply their entire labor endowment. Denoting the wage rate per effective unit of labor by $w$, a worker's labor income then is wa.

Labor demand and firm profits. Firms use labor in differentiated activities to produce the homogeneous consumption good. They differ in their level of technology $M_{i}$, which indicates the number of differentiated activities in a firm. It thus corresponds to the complexity of a firm's production process, or the extent of division of labor in the firm. A firm's level of technology depends on the entrepreneur's skill in a way detailed below.

A firm's production technology is summarized by the production function

$$
y_{i}=X_{i}^{\gamma}, \quad X_{i}=\left(\int_{0}^{M_{i}} n_{i j}^{\frac{\sigma-1}{\sigma}} \mathrm{d} j\right)^{\frac{\sigma}{\sigma-1}}, \quad \gamma \in(0,1), \sigma>1,
$$

where $y_{i}$ is output of firm $i, X_{i}$ is an aggregate of the differentiated labor inputs $n_{i j}$ it uses, and $M_{i}$ indicates the degree of complexity of its technology. The production function exhibits decreasing returns to scale. This can be interpreted to reflect any entrepreneur's limited span of control, as in Lucas (1978). It also ensures that firm size is determinate, implying a firm size distribution given any distribution of $M$ over firms. The elasticity of substitution among inputs is given by $\sigma$. Given that $M$ differs across firms and that thus not all firms use all types of differentiated inputs, it is natural to assume that different inputs are gross substitutes $(\sigma>1)$. Heterogeneity in $M$ plays a role as long as they are imperfect substitutes, as shown below. ${ }^{21}$ Importantly, the production function exhibits love of variety, and firms with larger $M$ are more productive.

The firm's profit maximization problem can be solved using a typical two-stage approach: choose inputs $n_{i j}$ to minimize the cost of attaining a given level of the input aggregate $X_{i}$, and then choose $X_{i}$ to maximize profit. The solution to the latter will depend on a firm's productivity $M_{i}$.

Denoting desired output by $\bar{y}$ and defining $\bar{X}=\bar{y}^{1 / \gamma}$, the solution to the cost minimization

interpreted in terms of heterogeneity in risk aversion.

${ }^{21}$ The formulation in equation (1) is isomorphic to one where final goods firms use (a heterogeneous number of) differentiated intermediate products, intermediates are produced using a production function that is linear in labor, and there is perfect competition in each intermediate goods sector. Monopolistic competition in intermediate goods can also be accommodated easily and would just require a remapping of parameters. In the quantitative exercise in Section 5, a more general specification is chosen in which intermediates are produced using capital and labor with constant returns to scale. 
problem yields the firm's labor demand function for each activity $j$ as

$$
n_{j}(M)=\left(\frac{w}{\lambda(M)}\right)^{-\sigma} \bar{X} \quad \forall j
$$

where $\lambda$ is the marginal cost of another unit of $X$. With constant returns to scale for transforming the differentiated labor inputs into $X, \lambda$ is independent of $X$ and equals $M^{\frac{1}{1-\sigma}} w$, and the demand for each $n_{j}$ becomes

$$
n_{j}(M)=M^{\frac{-\sigma}{\sigma-1}} \bar{X} \quad \forall j
$$

Because of greater specialization in firms using more complex technologies, their marginal cost of $X, \lambda$, is lower. As a consequence, they require less of each input to produce $\bar{y}$. Because a larger $M$ allows a firm to produce more output from a given quantity of inputs, I will in the following refer to $M$ as the firm's productivity. While $M$ does not equal TFP, it maps one-to-one with TFP.

Choice of $\bar{X}$ to maximize profits yields optimal output and profits as

$$
y(M)=\left(\frac{w}{\gamma}\right)^{\frac{-\gamma}{1-\gamma}} M^{\frac{1}{\sigma-1} \frac{\gamma}{1-\gamma}}, \quad \pi(M)=(1-\gamma) y(M)
$$

Both output and profits increase in $M$. They are convex in $M$ if $\gamma>\frac{\sigma-1}{\sigma} .^{22}$ As this inequality holds for reasonable sets of parameter values (e.g. $\gamma=0.9$ and $\sigma<10$ ), I will from now on assume that it is satisfied.

Skills and technology. Entrepreneurs run firms and collect their firm's profits. The crucial activity involved in running a firm is setting up and overseeing a technology involving $M_{i}$ differentiated activities. Agents differ in their skill in doing this.

To capture this, suppose that an entrepreneur's time endowment is fixed at 1 , and that overseeing an activity takes $c(a, \bar{M})$ units of time, where $\bar{M} \geq 1$ is a measure of aggregate technology. Since profits increase in $M$, each entrepreneur chooses to oversee as many activities as possible given limited time. This implies that $M(a, \bar{M})=1 / c(a, \bar{M})$. Also suppose that $\partial c / \partial a<0$ and $\partial c / \partial \bar{M}<0$. The first assumption implies that more able individuals can manage more complex production processes and thus run more productive firms. ${ }^{23}$ The second assumption implies that, conditional on an entrepreneur's skill, any

\footnotetext{
${ }^{22}$ A low $\gamma$ implies more quickly decreasing returns to scale. As a result, optimal size responds less to productivity, and benefits from being more productive are not as large, implying less convex $\pi(M)$. High $\sigma$ implies that inputs are more substitutable, so the benefit of being able to use more of them declines.

${ }^{23}$ Galí (1995) uses a similar setup with choice of $M$ for a representative firms. Yet, this is a natural place
} 
firm is more productive when situated in a technologically more advanced economy. This links aggregate output to $\bar{M}$. Finally, assume that $\partial^{2} c /(\partial \bar{M} \partial a)<0$. This is "skill-biased change in entrepreneurial technology". It captures that, while all entrepreneurs benefit from improvements in aggregate technology $\bar{M}$, more skilled entrepreneurs benefit more.

For concreteness, suppose that $c(a, \bar{M})=\bar{M}^{-a}$. This functional form is similar to the one often chosen for the marginal cost of innovation in the literature on endogenous growth with R\&D. The presence of $a$ in the exponent is akin to introducing heterogeneity in the parameter that controls how existing knowledge affects the productivity of R\&D in e.g. Jones (1995). ${ }^{24}$ More skilled entrepreneurs are better at drawing on existing knowledge. They are better at exploiting similarities and synergies between different activities, therefore can oversee more of them, and are more productive. As technology advances, the potential for exploiting synergies grows, and more skilled entrepreneurs benefit more from the new technologies.

With this specification, the most able entrepreneurs $(a=\bar{a})$ operate at the technological frontier, the least able ones $(a=0)$ at the lowest level, and intermediate ones at some distance to the frontier. The position of a firm relative to the frontier, $m(a, \bar{M})=$ $M(a, \bar{M}) / M(\bar{a}, \bar{M})=\bar{M}^{a-\bar{a}}$, is bounded between 0 and 1 . Crucially, for low levels of the frontier, all firms are close to it. The higher the frontier, the more dispersed the levels of technology of potential firms. The actual distribution of technology among active firms depends on occupational choice.

Occupational choice. Occupational choice endogenously determines the distributions of workers' ability and of firms' technologies. Since both the firm's and the worker's problem are static, individuals choose to become a worker if $w(\bar{M}) a>\pi(M(a, \bar{M}))$. Given the wage rate and the state of aggregate technology, the known value of an agent's ability thus is

to introduce heterogeneity. Linking complexity to the variety of inputs used is in line with Michaels's (2007) measure of complexity. Unfortunately, the heterogeneity of occupations prevents me from using his measure in the quantitative analysis in Section 5. The positive correlation of potential profits and earnings $w a$ is in line with empirical evidence showing that more educated individuals earn both higher wages and make more profits as entrepreneurs; see e.g. Evans and Leighton (1989) and Hamilton (2000). Rosen (1982) makes a similar assumption. With a different sign of the derivative, radically different occupational choice outcomes are possible, as shown by Jovanovic (1994) in a related setting. However, results are quite rich even with the natural assumption in the text.

${ }^{24}$ In that paper, the marginal cost of a unit of knowledge is proportional to $A^{-\phi}$, where $A$ is existing knowledge and $\phi$ governs the contribution of $A$ to new knowledge creation. The profit function resulting if $c(a, \bar{M})=\bar{M}^{-a}$ is also closely related to that in the multi-sector model in Murphy, Shleifer and Vishny (1991). There, more able entrepreneurs select into a sector where profits are more elastic with respect to their talent. Differently from here, however, Murphy et al. (1991) assume that aggregate productivity affects all firms' profits equally. 
sufficient for the choice. ${ }^{25}$ A population ability distribution then implies, via labor market clearing, an occupational choice for each $a$ and corresponding distributions of workers' ability and firms' productivity.

Because profits are continuous, increasing and convex in $a$, while wages are linear in $a$, it is clear that there is a threshold $a_{H}$ above which it is optimal to become an entrepreneur. If $a_{H}<\bar{a}$ (the upper bound on $a$ ), high-productivity firms are active in the economy. At the same time, from $(4), \pi(M(0))>0=w \cdot 0$, so that agents with ability between 0 and a threshold $a_{L}$ become entrepreneurs. Individuals with $a \in\left(a_{L}, a_{H}\right)$ choose to become workers.

The resulting occupational choice pattern is depicted in Figure 8, which plots the value of entrepreneurship (solid line) and of employment (line with crosses) against $a$, assuming $a_{H}<\bar{a}$. The lower threshold $a_{L}$ is always interior $(\in(0, \bar{a}))$, as otherwise the labor market does not clear. Low- and high- $a$ agents then become entrepreneurs, with intermediate- $a$ individuals choosing to become workers. This pattern persists when also considering additional heterogeneity that is orthogonal to that in $a$, e.g. differences in taste for entrepreneurship or in attitudes towards risk. This two-sided occupational choice pattern fits with evidence on the propensity to be an entrepreneur across the education and wage distribution reported above. It differs from the pattern usually obtained in this type of model, e.g. the individuals with the highest entrepreneurial ability (Lucas 1978) or the lowest risk aversion (Kihlstrom and Laffont 1979) choosing entrepreneurship. The self-employed in Gollin (2007) also have relatively high entrepreneurial ability and potential wages.

The model thus matches the empirical pattern that entrepreneurs tend to be drawn from the extremes of the ability distribution. Clearly, entrepreneurs running very large, successful firms are highly able. At the same time, there is an abundance of entrepreneurs running minuscule businesses with tiny profits, in particular in poor countries. For instance, Gindling and Newhouse (2012) show, using household data from 98 countries, that average education, household income and consumption are highest among employers and lowest among own-account workers, with employees lying in between. Poschke (2013b) shows that in U.S. National Longitudinal Survey of Youth (NLSY) data, individuals with high or low education are more likely to be entrepreneurs than individuals with intermediate education. (See that paper and Poschke (2013a) for more details.)

Matching this empirical selection pattern is key in an analysis of occupational choice. Given the abundance of small firms in poor countries, it is also very important in order to

\footnotetext{
${ }^{25} \mathrm{We}$ abstract from entry costs, sunk investment, search or other issues that would make the problem dynamic without necessarily substantially affecting results. Poschke (2013b) analyzes occupational choice with search for a good project.
} 
Figure 8: The values of employment $(W(a))$ and entrepreneurship $(V(a))$

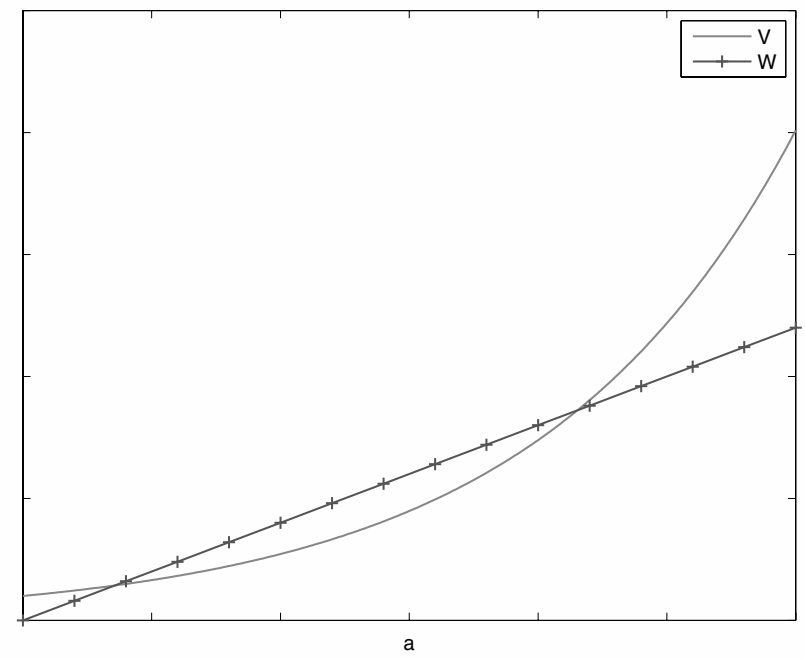

match the firm size distribution across countries. In the model, the activity of low-profit entrepreneurs - so abundant in the data - is due to the specific way in which technology and its relationship with ability is modelled here and need not necessarily arise with other ways of modelling heterogeneity in productivity and its relation to ability. Yet, while the specification chosen here delivers the existence of low-productivity firms somewhat directly, their owners' occupational choice arises naturally in more general settings with heterogeneity in productivity and pre-entry uncertainty about a project's merits, as shown in Poschke (2013b). More precisely, even if expected profits of the lowest-ability potential entrepreneur are zero or negative, this is not what matters because of the ability to reject bad projects. Once only sufficiently good projects are accepted, low-ability agents will choose entrepreneurship if projects that are preferred to employment exist, and they are sufficiently likely to find them. (Astebro, Chen and Thompson (2011) and Ohyama (2012) also present theories predicting that entrepreneurs are more likely to come from the extremes of the ability distribution.)

Equilibrium. An equilibrium of this economy consists in a wage rate $w$ and an allocation of agents to activities such that, taking $w$ as given, agents choose optimally between work and entrepreneurship, firms demand labor optimally, and the labor market clears.

Denoting the density of firms over $a$ by $\nu(a)$, their total measure by $B$, total effective labor supply by $N \equiv \int_{a_{L}}^{a_{H}} a \phi(a) \mathrm{d} a$, defining $\eta=\frac{1}{\sigma-1} \frac{\gamma}{1-\gamma}$, and using $M(a, \bar{M})=\bar{M}^{a}$, the 
equilibrium wage rate then is obtained from labor market clearing as

$$
w(\bar{M})=\gamma\left[\frac{B}{N} \int \nu(a) \bar{M}^{\eta a} \mathrm{~d} a\right]^{1-\gamma}
$$

where here and in the following the integral is over the set of entrepreneurs, $a \in\left[0, a_{L}\right] \cup$ $\left[a_{H}, \bar{a}\right]$. The free entry or optimal occupational choice condition is

$$
w(\bar{M}) a_{i}=\pi\left(a_{i}, \bar{M}\right)=(1-\gamma)\left(\frac{w}{\gamma}\right)^{\frac{-\gamma}{1-\gamma}} \bar{M}^{\eta a_{i}}, \quad a_{i}=a_{L}, a_{H}
$$

which can be rewritten as

$$
w=\left[(1-\gamma) \frac{\bar{M}^{\eta a_{L}}}{a_{L}}\right]^{1-\gamma} \gamma^{\gamma}=\left[(1-\gamma) \frac{\bar{M}^{\eta a_{H}}}{a_{H}}\right]^{1-\gamma} \gamma^{\gamma} .
$$

Equilibrium can be represented as the intersection of (LM) and (FEC) in $a_{L}, w$-space. $a_{H}$ then follows from the second equality in (FEC). Since (LM) implies a strictly positive relationship between $a_{L}$ and $w$ and (FEC) a strictly negative one, a unique equilibrium exists for any $\bar{M}$.

The model is easy to extend to capital as an input, to the production of intermediate goods outside the firm, with perfect or monopolistic competition, and to other dimensions of heterogeneity, e.g. in tastes or in risk aversion. The quantitative exercise in Section 5 will employ such a more general model.

\section{Development and the firm size distribution}

In this model, technological improvements affect occupational choice and, through this channel, the firm size distribution.

\subsection{The technological frontier and occupational choice}

Changes in the technological frontier affect incentives to become a worker or an entrepreneur both through their effect on potential profits and on wages. As technology advances, some firms stay close to the advancing frontier, while others fall behind. As a result, profits as a function of ability change, the populations of firms and workers change, and the equilibrium wage rate changes.

As $\bar{M}$ increases with development, (LM) and (FEC) both change. The derivative of (LM) 
with respect to $\bar{M}$, given $a_{L}$ and $a_{H}$, and thus $\nu(a), B$ and $N$, is

$$
(1-\gamma) \eta \frac{w}{\bar{M}} \int \nu(a) a \bar{M}^{\eta a}\left[\int \nu(a) \bar{M}^{\eta a}\right]^{-1}
$$

The derivative of (FEC) with respect to $\bar{M}$, given $a_{L}$ and $a_{H}$, is

$$
(1-\gamma) \eta a_{L} \frac{w}{\bar{M}}
$$

In $a_{L}, w$-space, both curves shift up as $\bar{M}$ rises, implying that the wage rate increases with $\bar{M}$. The change in $a_{L}$ is ambiguous and depends on the difference between the two derivatives, which is

$$
\Delta \equiv(1-\gamma) \eta \frac{w}{\bar{M}}\left[\int \nu(a) a \bar{M}^{\eta a} \mathrm{~d} a\left(\int \nu(a) \bar{M}^{\eta a} \mathrm{~d} a\right)^{-1}-a_{L}\right]
$$

If this equals zero, (FEC) and (LM) shift up by the same amount in response to an increase in $\bar{M}$, and $a_{L}$ does not change. If $\Delta$ is positive, (LM) shifts up more, and $a_{L}$ needs to decrease for both (FEC) and (LM) to hold: more marginal entrepreneurs would like to become workers, resulting in lower $a_{L}$. If $\Delta$ is negative, $a_{L}$ needs to rise.

Since the term in square brackets can take on negative and positive values, the sign of $\Delta$ is ambiguous. It is also clear that it can change with $\bar{M}$. For $\bar{M}=1$, profits are equal for all $a$, and only low- $a$ agents become entrepreneurs. In that situation, agents with $a_{L}$ are the most productive entrepreneurs so that the term in square brackets, and thus $\Delta$, is negative, implying that $a_{L}$ rises with $\bar{M}$.

Lemma 1 The derivative of $\Delta$ with respect to $\bar{M}$ is positive. It is bounded away from zero as long as there is dispersion in the productivity of active firms.

Proof See Appendix B.

Since $\Delta$ is negative for $\bar{M}=1$, implying rising $a_{L}$, but then increases and eventually turns positive, this result follows immediately:

Corollary 2 On an increasing path for $\bar{M}$ starting at $\bar{M}=1, a_{L}$ first increases, then declines.

The evolution of $a_{H}$ is tied to that of $a_{L}$ by the free entry condition. Taking the derivative of both equations in (FEC) with respect to $\bar{M}$ (see the Appendix for details) yields

$$
a_{i}^{\prime}=\frac{1}{\bar{M}} \frac{\varepsilon(w, \bar{M}) /(1-\gamma)-\eta a_{i}}{\eta \ln \bar{M}-1 / a_{i}}, \quad a_{i}=a_{L}, a_{H} .
$$


Since the right hand side of (FEC) is minimized at $\hat{a}=1 /(\eta \ln \bar{M})$, so that $\eta \ln \bar{M}-1 / \hat{a}=0$, and since $a_{L}<\hat{a}<a_{H}$, the denominator of (6) is negative at $a_{L}$ and positive at $a_{H}$. If the numerator is positive, a marginal entrepreneur benefits more from wage growth due to $\bar{M}$ than from profit growth and thus exits, implying lower $a_{L}$ or larger $a_{H}$.

Solving (6) for $\varepsilon(w, \bar{M})$ for $i=L, H$ and equating the resulting expressions implies

$$
a_{H}^{\prime}=\eta \frac{a_{L}-a_{H}}{\bar{M}\left(\eta \ln \bar{M}-1 / a_{H}\right)}+a_{L}^{\prime} \frac{\eta \ln \bar{M}-1 / a_{L}}{\eta \ln \bar{M}-1 / a_{H}} .
$$

By the properties of (FEC), the last fraction is negative, so that $a_{H}{ }^{\prime}$ is a decreasing function of $a_{L}{ }^{\prime}$. Because $a_{L}<a_{H}$, the intercept is negative. Hence, there is a value $\hat{a}_{L}^{\prime}<0$ such that $a_{H}{ }^{\prime}$ is negative if $a_{L}{ }^{\prime}>\hat{a}_{L}^{\prime}$ and positive otherwise. From this it follows that

Proposition 3 Development can be partitioned into three phases:

$$
\begin{array}{ll}
\text { P0 : } & a_{L}^{\prime}>0, a_{H}^{\prime}<0 \\
\text { P1 : } & a_{L}^{\prime}<0, a_{H}^{\prime}<0 \\
\text { P2 : } & a_{L}^{\prime}<0, a_{H}^{\prime}>0
\end{array}
$$

The economy is in $\boldsymbol{P O}$ if $\bar{M}=1$ and traverses the phases in sequence as $\bar{M}$ increases.

Corollary 4 The distance between the thresholds $a_{L}$ and $a_{H}$ shrinks with $\bar{M}$ in $\boldsymbol{P O}$ and in a first part of $\boldsymbol{P} \mathbf{1}$, and then grows with $\bar{M}$ in the remainder of $\boldsymbol{P} \mathbf{1}$ and in $\boldsymbol{P} \mathscr{2}$.

Proof The result is obvious for $\mathbf{P 0}$ and for $\mathbf{P 2}$. In $\mathbf{P 1}$, (7) implies that $a_{H}^{\prime}-a_{L}^{\prime}>0$ if

$$
a_{L}^{\prime}<\frac{\eta}{\bar{M}} \frac{a_{H}-a_{L}}{1 / a_{H}-1 / a_{L}}<0 .
$$

In $\mathbf{P 1}, a_{L}^{\prime}$ initially is zero (by definition) and then declines. The thresholds $a_{L}$ and $a_{H}$ begin moving apart once $a_{L}^{\prime}$ passes the threshold given in (8).

Corollary 5 In the three phases, the measure of active firms B evolve as follows:

$$
\begin{array}{ll}
\text { P0 : } & B^{\prime}>0 \\
\text { P1 : } & B^{\prime}<0 \\
\text { P2 : } & B^{\prime}<0
\end{array}
$$

Proof It is clear that in P0 (P2), $B$ rises (declines), since $a_{L}$ and $a_{H}$ move in opposite directions. In $\mathbf{P} 1$, both decline. How does this affect $B ? \partial B / \partial \bar{M}=a_{L}{ }^{\prime} \phi\left(a_{L}\right)-a_{H}{ }^{\prime} \phi\left(a_{H}\right)$. 
Since labor demand increases in $a, \partial B / \partial \bar{M}=0$ would imply an increase in labor demand: the firms that enter due to declining $a_{H}$ demand more labor than that released by the firms that exit due to declining $a_{L}$. At the same time, labor supply would decline, as entering entrepreneurs withdraw more labor supply from the labor market than exiting entrepreneurs contribute. For an equilibrium, it must thus be that the measure of exiting entrepreneurs exceeds that of entering ones, and $B$ declines.

In the following, I will ignore $\mathbf{P 0}$ for lack of empirical relevance. ${ }^{26}$ Phases $\mathbf{P} \mathbf{1}$ and $\mathbf{P} \mathbf{2}$ are characterized by an entrepreneurship rate that declines as output grows, and by increasing dominance by high-productivity entrepreneurs. What drives this development? Consider the elasticities of wage income and profits with respect to $\bar{M}$, keeping $a_{L}$ and $a_{H}$ constant:

$$
\begin{aligned}
\varepsilon(\pi(\cdot), \bar{M}) & =\eta a-\frac{\gamma}{1-\gamma} \varepsilon(w, \bar{M}) \\
\varepsilon(w(\cdot) a, \bar{M}) & =\frac{\gamma}{\sigma-1} \int \nu(a) a \bar{M}^{\eta a} \mathrm{~d} a\left[\int \nu(a) \bar{M}^{\eta a} \mathrm{~d} a\right]^{-1}
\end{aligned}
$$

An advance in the frontier has two effects on profits: it improves every firm's technology (the first term), but it also raises the wage rate (the second term), which is a drag on profits. As the effect of higher wages is independent of $a$, it is clear that only firms with high enough $a$ benefit from aggregate technology improvements. Low- $a$ firms lose more to the wage increase than they gain from the productivity improvement. Wages, in contrast, unambiguously increase with advances in the technological frontier. As a consequence, the composition of the firm size distribution changes as technology advances.

Note that if all agents had the same ability $a$, both $\varepsilon(w, \bar{M})$ and $\varepsilon(\pi(a), \bar{M})$ would reduce to $\frac{a \gamma}{\sigma-1}$. As a consequence, wages and profits would increase in sync with technological advances, and occupational choice would remain unaffected, i.e. the thresholds $a_{L}$ and $a_{H}$ constant. Only with heterogeneity in a do some agents benefit more than others from advances in the frontier, and occupational choices change.

This shows that as $\bar{M}$ increases, an agent that previously was indifferent between entrepreneurship and wage work now chooses entrepreneurship if

$$
\eta a>\frac{\gamma}{1-\gamma} \varepsilon(w(\cdot) a, \bar{M})
$$

\footnotetext{
${ }^{26}$ In the quantitative exercise, this phase turns out to be very short, and to occur only for values of $\bar{M}$ below those of the poorest country in the GEM sample (Uganda).
} 
Defining $\tilde{a}$ as the level of $a$ at which (11) holds with equality yields

$$
\tilde{a}=\frac{\sigma-1}{\gamma} \varepsilon(w(\cdot) a, \bar{M})=\int \nu(a) a \bar{M}^{\eta a} \mathrm{~d} a\left[\int \nu(a) \bar{M}^{\eta a} \mathrm{~d} a\right]^{-1} .
$$

Then, as $\bar{M}$ increases, indifference of agents with $a>\tilde{a}$ is broken in favor of entrepreneurship, while indifference of agents with $a<\tilde{a}$ is broken in favor of wage work. Note that $\tilde{a}>0$, that $\tilde{a}$ is equal to the productivity of active firms if all active firms have the same level of $a$, and that $\tilde{a}$ is below $a$ of the most productive firm if firms of different levels of $a$ coexist.

Intuitively, whether a firm gains or loses depends on its productivity relative to a complicated moment of the productivity distribution. This is because advances in the frontier increase labor demand and wages, and thereby all firms' costs. They also improve firms' productivity - but only firms that can make use of most of the advance in the frontier benefit sufficiently from this. Low- $a$ firms are squeezed: they are fully exposed to wage increases due to advances in the frontier, while being unable to translate these into large improvements in their own productivity.

The position of $\tilde{a}$ relative to the thresholds $a_{L}$ and $a_{H}$ can also be related to the phases P0 to P2. When $\tilde{a}<a_{L}, \Delta<0$ and the economy is in P0. In this phase, firms with $a \in\left(\tilde{a}, a_{L}\right)$ benefit from increasing $\bar{M}$. Hence, $a_{L}$ increases with $\bar{M}$. Firms at $a_{H}$ and above also benefit, so $a_{H}$ falls. However, as $\bar{M}$ rises, $\tilde{a}$ increases, just like $\Delta$. As a consequence, $\tilde{a}$ eventually reaches and passes $a_{L}$. At that point, $\Delta$ turns positive, firms at $a_{L}$ cease to be net beneficiaries of technical change, and $a_{L}$ starts to decline. Firms at $a_{H}$ continue to benefit, so $a_{H}$ continues to decline. This is $\mathbf{P} 1$. Once $\tilde{a}$ reaches and passes $a_{H}$, the economy enters P2. In this phase, entrepreneurs at $a_{H}$ are net losers from technical progress, and they exit as $\bar{M}$ increases.

Figure 9 shows the evolution of occupational choice as $\bar{M}$ increases. The left panel shows profits and wages as functions of ability for two levels of $\bar{M}$. As in Figure 8, the straight lines correspond to wages and the curved ones to profits, and $a_{L i}$ and $a_{H i}(i=1,2)$ indicate the choice thresholds.

The left panel illustrates how occupational choice changes with $\bar{M}$. Higher $\bar{M}$ raises the productivity of all firms and thereby leads to higher wages: the wage line pivots up from the straight dash-dot line to the straight dotted line. Higher productivity raises profits (they change from the dashed to the solid line), except for some firms of low- $a$ entrepreneurs for who the productivity increase is so small that it is outweighed by the increase in wages. This unambiguously makes entrepreneurship more attractive for the highest-ability agents, and less so for the ones with the lowest ability. In the situation drawn in the figure, the economy 


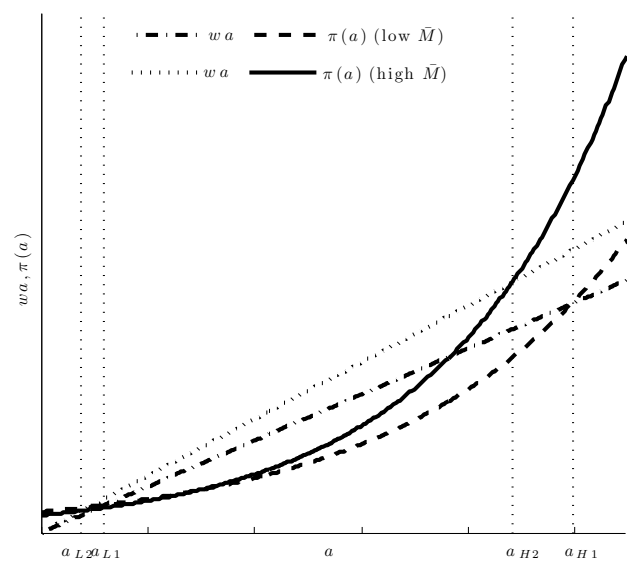

(a) Occupational choice for two values of $\bar{M}$

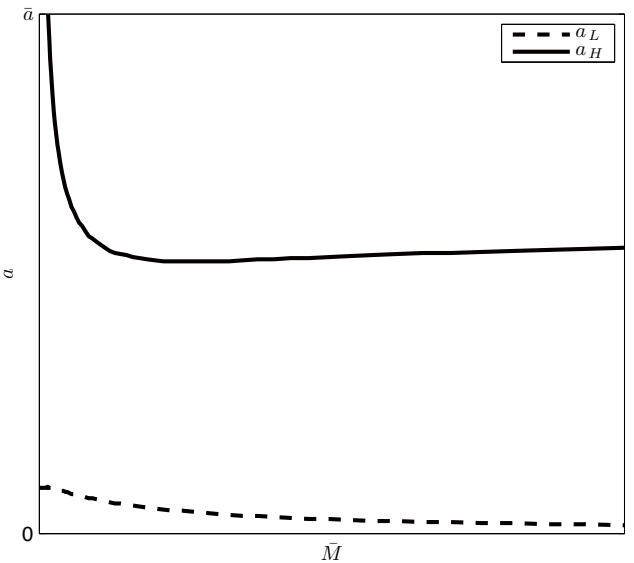

(b) The evolution of the thresholds $a_{L}$ and $a_{H}$ with increasing $\bar{M}$

Figure 9: Occupational choice as $\bar{M}$ increases

is in $\mathbf{P 1}$, and entrepreneurs with $a$ just below $a_{H 1}$ still benefit and agents at or just below $a_{L 1}$ lose from higher $\bar{M}$. As a result, $a_{H}$ falls from $a_{H 1}$ to $a_{H 2}$, and $a_{L}$ falls from $a_{L 1}$ to $a_{L 2}$. It is mainly higher labor demand from top firms and the entry of new relatively productive firms between $a_{H 1}$ and $a_{H 2}$ that drives wages up.

The right panel shows the values taken by $a_{L}$ and $a_{H}$ for a "history" of increasing $\bar{M}$. Starting from low $\bar{M}$, increases in $\bar{M}$ reduce both $a_{H}$ and $a_{L}$, as in the left panel of the figure. This corresponds to Phase $\mathbf{P} 1 .{ }^{27}$ Once most low-productivity firms are gone, firms with $a=a_{H}$, while run by relatively high-ability individuals, actually have low productivity compared to other firms in the economy. From this point on, further advances in $\bar{M}$ raise profits less than wages for firms with $a=a_{H}$, and the upper threshold $a_{H}$ shifts up again. This signals the beginning of Phase P2. As $\bar{M}$ increases further, $a_{L}$ falls further, but approaches zero only asymptotically. The upper threshold $a_{H}$ also continues to rise, albeit at a slow pace. As a result, for very high levels of the frontier, almost all active firms have high productivity.

Advancing technology does not lift all boats here. By assumption, the most able agents benefit most from advances in the technological frontier, as they can deal more easily with the increased complexity and use a larger fraction of the new technologies. Low-ability entrepreneurs benefit less. In fact, increasing wages due to higher productivity at top firms (wage earners always gain from technological improvements) mean that the least productive firms' profits fall as technology improves. As a consequence, marginal low-productivity

\footnotetext{
${ }^{27}$ Phase $\mathbf{P 0}$ is very brief, and covers the lowest values of $\bar{M}$, at the very left edge of the figure.
} 
entrepreneurs convert to become wage earners, and eventually also do better, though not necessarily immediately. The lowest-ability agents $(a=0)$ always lose. Technology improvements thus have a negative effect on low-productivity firms that operates through wage increases.

\subsection{Advances in the technological frontier and the firm size dis- tribution}

As occupational choices change, the firm size distribution changes. The following describes how average firm size, size dispersion and skewness change with increasing $\bar{M}$.

Given that the average worker supplies $N /(1-B)$ efficiency units and that the average firm uses $N / B$ efficiency units, average employment in terms of workers is $(1-B) / B$. Since $B$ declines with $\bar{M}$, this increases in $\bar{M}$. The model thus reproduces Facts 1 and 3 . Whether it matches Fact 2 (fewer small firms in richer countries) is a quantitative question, as it depends on the threshold for separating large and small firms.

Percentiles of the size distribution also change with $\bar{M}$ in the model. Let $\mathcal{V}(a)$ be the $c d f$ associated with $\nu(a)$. Then percentiles of the size distribution above $\mathcal{V}\left(\max \left(a_{H}, a_{H}+a_{H}^{\prime}\right)\right)$ increase with $\bar{M}$ and those below $\mathcal{V}\left(a_{L}+a_{L}^{\prime}\right)$ decrease with $\bar{M}$ in $\mathbf{P} \mathbf{1}$ and $\mathbf{P} 2$. The reason for this, too, is that in $\mathbf{P 1}$ and $\mathbf{P 2}$, due to changing occupational choices, $B$ declines with $\bar{M}$. Hence, the probability mass above $a_{L}+a_{L}^{\prime}$ decreases. As a consequence, $\mathcal{V}(a)$ increases for all $a<a_{L}+a_{L}^{\prime}$, and conversely, the value of $a$ increases at each percentile below $\mathcal{V}\left(a_{L}+a_{L}^{\prime}\right)$. The argument above $a_{H}$ is analogous and applies to $a$ above $a_{H}$ in $\mathbf{P} \mathbf{1}$ and to $a$ above $a_{H}+a_{H}^{\prime}$ in P2. If the median firm's $a$ exceeds $a_{H}$, the model thus matches the increase in employment at the median and at higher percentiles seen in Fact 4. The employment decline at lower percentiles suggested by the model is not visible in the data due to integer restrictions firms at these percentiles typically have very few employees. Even in the U.S., the 10th and 25th percentiles of the employment distribution are 0 and 1 , respectively. ${ }^{28}$

Next, the interquartile ratio increases with $\bar{M}$ in $\mathbf{P} \mathbf{1}$ and $\mathbf{P} \mathbf{2}$ if the 75 th percentile of the size distribution is above $\max \left(a_{H}, a_{H}+a_{H}^{\prime}\right)$ and the 25 th below $a_{L}+a_{L}^{\prime}$. The model

\footnotetext{
${ }^{28}$ How does this fit with Hsieh and Klenow's (2009) finding of larger TFP dispersion in China than in the U.S. (keeping in mind the measurement issues discussed in footnote 19)? The long left tail of the Chinese productivity distribution visible in their Figure I suggests a large distortion of the entry and exit margin when seen through the lens of standard heterogeneous firm models (Hopenhayn (1992); see also Samaniego (2006), Barseghyan (2008), Poschke (2010) and Moscoso Boedo and Mukoyama (2012)). Given that their high size cutoff probably excludes from their data almost all the rather small firms run by low-ability entrepreneurs, this corresponds to a downward distortion of $a_{H}$ in the present context. If this distortion is large in a poor country, the model can generate higher productivity dispersion of firms with $a>a_{H}$ in the poorer country. Dispersion computed using firms of all sizes will however still be larger in the richer country, as it is in the data.
} 
thus matches Fact 5 in this case. How skewness changes with $\bar{M}$ is a quantitative question. Supposing that the median firm has $a>a_{H}$, the median and the 90th percentile of the size distribution both increase with $\bar{M}$, while the 10th percentile declines. The net change in the skewness measure used in Fact $6,\left(\left(p_{90}-p_{50}\right)-\left(p_{50}-p_{10}\right)\right) /\left(p_{90}-p_{10}\right)$, then depends on the relative size of these changes. ${ }^{29}$

The model thus qualitatively reproduces all facts reported in Section 2, except for Fact 6 , which remains a quantitative issue. The next section takes a further step and explores the quantitative fit of the model.

\section{Quantitative exercise: occupational choice and en- trepreneurship across countries}

How well do the historical experience of one country and cross-country patterns accord? This gives an indication of how relevant the mechanisms in the model are relative to other factors affecting entrepreneurship and the firm size distribution.

To explore this, I calibrate the model to the U.S. experience and then evaluate how well it fits across a broad set of countries; in particular, how well it mimics the empirical relationships shown in Section 2. This corresponds to attempting to explain observed crosscountry differences in firm size distributions purely with technological factors - an exercise that turns out work surprisingly well.

\subsection{Generalized model}

For the quantitative exercise, it is useful to generalize the very stylized model from Section 3 slightly. I introduce three modifications: production of intermediates with capital and labor, heterogeneity in taste for entrepreneurship, and a more general specification of $M(a)$.

Capital. In the simple model in Section 3, the differentiated activities used for producing final output use labor only. The aggregate input $X$ has constant returns to scale in all labor inputs. Replace this by

$$
X=\left(\int_{0}^{M_{i}}\left(n_{j}^{\alpha} k_{j}^{1-\alpha}\right)^{\frac{\sigma-1}{\sigma}} \mathrm{d} j\right)^{\frac{\sigma}{\sigma-1}}
$$

\footnotetext{
${ }^{29}$ The change in skewness similarly is a quantitative question for the other measure of skewness presented for Fact 6 and shown in Figure 14 and in Table 5.
} 
i.e., production of intermediates with capital and labor. This allows setting $\alpha$ and $\gamma$ to match income shares in the data. Firms' optimization is as in Section 3, taking the wage rate $w$ and the rental rate of capital $r$ as given. Households, who own the capital stock and rent it to firms, now face a capital accumulation decision. Their Euler equation, evaluated at the steady state of the economy they live in (thus, given its $\bar{M}$ ), prescribes equating the rental rate of capital net of depreciation to the rate of time preference. Assuming a common rate of time preference $\rho$ and a common depreciation rate $\delta$, this implies $r=\rho+\delta$. The firm's optimality condition for capital then pins down the aggregate capital stock. ${ }^{30}$

Taste heterogeneity. In the model of Section 3, only agents with $a<a_{L}$ or $a>a_{H}$ become entrepreneurs. Given the one-to-one mapping between $a$ and $M$, this implies a bimodal firm size distribution with only low- and high-productivity firms, but no firms with intermediate productivity. This is clearly counterfactual. Incorporating heterogeneity in tastes for entrepreneurship into the model allows to "fill in" the hole in the middle of the firm size distribution, while also adding realism. Indeed, most empirical studies of entrepreneurship point to some role for heterogeneity in tastes or risk aversion for entrepreneurship (see e.g. Hamilton 2000, Hurst and Pugsley 2011).

Thus, suppose that agents differ in their taste for entrepreneurship $\tau$. Define this such that individuals choose entrepreneurship if $\tau \pi(a)>w \cdot a \cdot \tau>1$ then implies "enjoyment" of entrepreneurship. If agents enjoy entrepreneurship, they will choose it even if $\pi(a)<w \cdot a$. Whether on average agents enjoy entrepreneurship is an empirical question; therefore the distribution of $\tau$ has to be calibrated, and the mean could be different from 1. A mean below 1 indicates that on average, individuals do not enjoy entrepreneurship.

With this additional dimension of heterogeneity, there are entrepreneurs of all levels of ability, and the productivity distribution can be unimodal if the ability distribution is so. However, individuals of high or low ability are still more likely to become entrepreneurs. Changes in $\bar{M}$ shift the relationship of $\pi(a)$ and $w a$ and therefore the taste threshold for entering entrepreneurship, resulting in an evolution of the proportion of agents with a given $a$ who are entrepreneurs.

Heterogeneity in risk aversion combined with a simple extension of the model would yield similar results. Suppose that wage income is certain and equals wa every period. Business income is a function of the entrepreneur's ability and of an uninsurable iid shock every period. (This reflects the higher variance of income from entrepreneurship; fluctuating

\footnotetext{
${ }^{30}$ While growth in $\bar{M}$ leads to changes in occupational choice and in the share of entrepreneurs, the setting is consistent with balanced growth since increases in $\bar{M}$ constitute labor-augmenting technical progress and the aggregate production function exhibits constant returns to scale (King, Plosser and Rebelo 1988). Results in this section can thus also be interpreted as developments along the balanced growth path of an economy.
} 
wages could easily be accommodated, too.) Define the shock such that profits are given by $s_{t} \pi(a)$, where $s$ has mean 1 and variance $\sigma_{\pi}^{2}$. Let the period utility function be $u(c)=$ $c^{1-\rho} /(1-\rho)$, where the coefficient of relative risk aversion $\rho$ can vary across people. Then higher risk aversion $\rho$ or variance of profits $\sigma_{\pi}^{2}$ make entrepreneurship less attractive. The parametrization of heterogeneity in $\tau$ in the next section can thus alternatively be interpreted as describing variation in risk aversion. Because the setting with risk aversion contains more free parameters and also raises issues of the dynamic behavior of profits, I will pursue the taste interpretation in the remainder of the paper.

The technological frontier and complexity. How much additional complexity do advances in the technological frontier comport? The simple specification of $M(a)$ chosen in Section 3 restricted this relationship. But it is of course an empirical issue. Therefore, in this section, let the time cost of using an activity be

$$
c(a, \bar{M})=\bar{M}^{-\frac{a}{\lambda}-1}
$$

implying that a firm's technology be given by

$$
M(a, \bar{M})=\bar{M}^{\frac{a}{\lambda}+1}
$$

and that its position relative to the frontier is

$$
m(a, \bar{M})=\frac{M(a, \bar{M})}{M(\bar{a}, \bar{M})}=\bar{M}^{\frac{a-\bar{a}}{\lambda}} .
$$

The lower $\lambda$, the faster low-ability entrepreneurs fall behind the technological frontier as it advances. Note that this relationship contains two parameters: $\lambda$ and $\bar{M}$, which is an important parameter in its own right. They enter equation (15) sufficiently differently that both can be calibrated, using information from the U.S. time series.

\subsection{Calibration}

The model is calibrated to U.S. data. Some parameters can be set using standard numbers from the literature, while the remaining ones are calibrated to match a set of moments describing the U.S. economy. Note in particular that $\bar{M}$ has important effects on endogenous variables and can therefore be calibrated using U.S. data.

The share parameters $\gamma$ and $\alpha$ are set to generate a profit share of income of $10 \%$ and a labor share of two thirds. This implies a $\gamma$ of 0.9 and an $\alpha$ of 0.74 . The elasticity of 
substitution among intermediate inputs is set to 4, which is about the 75th percentile of the distribution of $\sigma$ across 4-digit industries estimated by Broda and Weinstein (2006). ${ }^{31}$ Setting the rate of time preference to $4 \%$ and the depreciation rate to $10 \%$ per annum implies a rental rate of capital of $14 \%$.

For the remaining parameters, first suppose that the ability and taste distributions are lognormal. A lognormal ability distribution implies that the wage distribution would be lognormal if everyone was an employee. With taste heterogeneity, entrepreneurs will come from across the ability distribution, and the wage distribution will be close to lognormal. For tastes, a lognormal distribution also seems natural, as they affect payoffs multiplicatively. Letting $\ln a \sim N\left(\mu_{a}, \sigma_{a}\right)$ and $\ln \tau \sim N\left(\mu_{\tau}, \sigma_{\tau}\right)$ and normalizing $\mu_{a}$ to be zero, the remaining moments to be calibrated are $\sigma_{a}, \mu_{\tau}, \sigma_{\tau}, \lambda$ and $\bar{M} \cdot{ }^{32}$

Data and model moments are shown in Table 2. U.S. data is for the year 2000, or close years where data for that year is not available. To pin down the parameters, information about the firm size distribution, about the distribution of wages and about the link between the two is needed. Targets are chosen accordingly: ${ }^{33}$ Average employment is informative about $\mu_{\tau}$, the mean taste for entrepreneurship. In an analysis of occupational choice, the broadest possible set of firms run as full-time concerns should be considered, so the target combines information from the Census Businesses Dynamics Statistics (BDS) on employer firms with CPS data on the self-employed reported in Hipple (2010) that is informative about full-time entrepreneurs without employees. Wage inequality, measured as the ratio between the 90th and the 10th percentile of the wage distribution, is taken from Autor, Katz and Kearney (2008, Figure 2.A) and helps to pin down $\sigma_{a}$. Changes in $\sigma_{\tau}$ affect occupational choice, in particular for small firms where $\pi(a)$ and $w a$ are not far apart. A statistic that is informative about it is the share of firms with less than average employment, computed from the GEM data for the US to take advantage of the more detailed size information. (Using the less detailed Census BDS and CPS data would yield similar results.) As seen in the previous section, the level of $\bar{M}$ also affects the dispersion of the firm size distribution. To capture this, I target the interquartile range standardized by mean firm size, combining size class data from the Census Statistics of U.S. Businesses (SUSB) and from the CPS (for non-employers). This measure of dispersion is robust to outliers, something especially important with a distribution that is as skewed as the firm size distribution. ${ }^{34}$

\footnotetext{
${ }^{31}$ Results are robust to setting $\sigma$ substantially higher, to 6 . This is although the sensitivity of profits with respect to $\bar{M}$ declines with $\sigma$ (see e.g. equation (4)).

${ }^{32}$ Setting $\mu_{a}=0$ is a normalization because changes in $\mu_{a}$ can be undone by changing $\lambda$ appropriately.

${ }^{33}$ In fact, the five parameters have to be calibrated jointly. While the following discussion stresses the main informational contribution of individual targets, parameters and target choices actually interact.

${ }^{34}$ Many thanks to Lori Bowan at the Census Bureau for providing a table with 1997 firm counts in detailed
} 
Finally, to separate $\lambda$ and $\bar{M}$, information on changes over time is needed. It would be most straightforward to use e.g. average firm size in 1900 in addition to average firm size in 2000, but there is no single series that encompasses both dates. An alternative is to use the elasticity of average firm size with respect to output per worker. This can be computed using any of the average firm size series plotted in Figure 2.2. They imply elasticities between 0.12 and 0.57. While the Dun \& Bradstreet series is longest (1890-1983), the figure suggests that it may overstate the increase in average firm size in the post-war period. To be conservative, I therefore target an elasticity of 0.34 , which is in the middle of the range in the data. Moreover, this value is close to the ones implied by the recent BDS series (1988-2006) and by the BEA Survey of Current Business series when omitting the Great Depression years.

Table 2: Calibration: Data and model moments

\begin{tabular}{lcc}
\hline & model & data \\
\hline average employment $\bar{n}$ & 11.5 & 11.5 \\
firm size iqr $/ \bar{n}$ & 0.26 & 0.26 \\
fraction firms with $n<\bar{n}$ & 0.85 & 0.85 \\
$\ln 90 / 10$ wage ratio & 1.64 & 1.62 \\
$\varepsilon(\bar{n}, Y)$ & 0.34 & 0.34 \\
\hline
\end{tabular}

Sources for data moments: average firm size Census Business Dynamics Statistics (BDS) and CPS data as reported in Hipple (2010); interquartile range (iqr) from Census Statistics of U.S. Businesses (SUSB) tabulations; fraction firms with $n<\bar{n}$ from GEM, see Section 2.1.1; wage ratio from Autor et al. (2008, Figure 2A); elasticity of average employment with respect to output per worker uses average firm size data plotted in Figure Figure 2.2 combined with data on non-farm employment from the BLS and from Weir (1992, Table D3), reprinted in Carter et al. (2006), and data on non-farm output from the BEA (http://www.bea.gov/bea, Table 1.3.6) and from U.S. Department of Commerce (1975, Series F128).

Values of the calibrated parameters are reported in Table 3. On average, individuals do not like entrepreneurship (the implied average $\tau$ in the population is clearly below 1 ), and thus require a premium before they take it up. There is substantial variation, however. Also note that the $\bar{M}$ resulting from the calibration describes the U.S. level of technology in 2000. To evaluate cross-country patterns, it will be necessary to set other countries' $\bar{M}$ relative to the U.S. level such that the output ratios match the data. The model-generated "time series" of average employment in the U.S. is plotted against non-farm output per worker in Figure 10. As the calibration fits the observed elasticity of 0.34 well, the series of average

size categories. To be able to use this larger detail, I use these Census SUSB data instead of the close BDS data discussed above for computing this statistic. Given the predominance of small firms in all firm counts, I would expect the BDS to yield a similar number. 
employment also fits well. ${ }^{35}$

Table 3: Calibrated parameter values

\begin{tabular}{ccccc}
\hline \multicolumn{7}{c}{ from external sources: } \\
$\gamma$ & $\alpha$ & $\sigma$ & $\rho$ & $\delta$ \\
0.9 & 0.74 & 4 & 0.04 & 0.1 \\
\hline \multicolumn{5}{l}{ from fitting } \\
$\sigma_{a}$ & $\mu_{\tau}$ & $\sigma_{\tau}$ & $\lambda$ & $\bar{M}$ \\
0.658 & -1.609 & 0.999 & 35.583 & 1811.7 \\
\hline
\end{tabular}

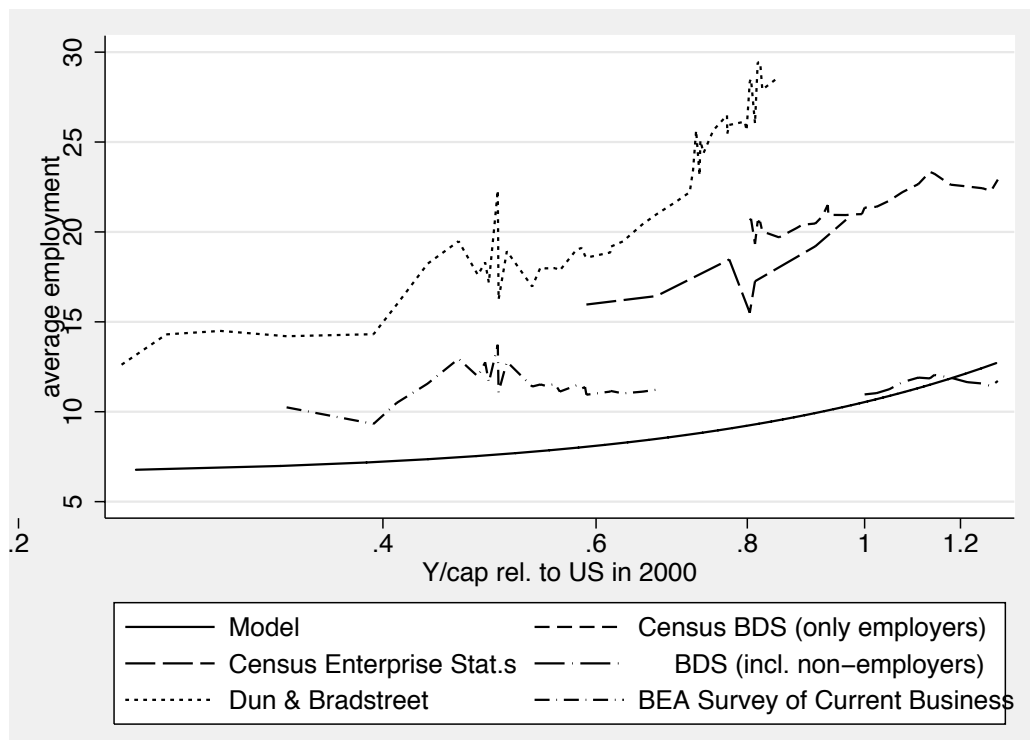

Figure 10: Average firm employment over U.S. history, data and model

Sources: Model results plus sources given in notes to Figure Figure 2.2 and Table 2.

An interesting dimension that has not been targeted in the calibration is the evolution of income inequality. Overall income inequality in the model increases more than wage inequality, as entrepreneurs' incomes lie at the extremes of the income distribution. Figure 11 reports the income shares of the top $10 \%$ and $1 \%$ in the U.S. income distribution for the data (from Piketty and Saez 2006, for 1950-2002) and for the model, plotted against U.S.

\footnotetext{
${ }^{35}$ While the model fits the short series of recent data well, it is evident that it could still fit rather well if a different average size target from one of the other sources covering a narrower population of firms were used.
} 
GDP per capita relative to its level in 2002. It is not surprising that inequality in the model does not reach its level in the data, as the model has no mechanism generating a fat right tail of the income distribution. What is remarkable, however, is that the trend in the model essentially replicates the trend in the data. For instance, from the mid-1960s to 2002, the income share of the top $1 \%$ increased by 6.6 percentage points. The model captures two thirds of this increase. It only misses the jump in U.S. income inequality that is known to have occurred in the 1980 s (at about $75 \%$ of 2002 GDP per capita).

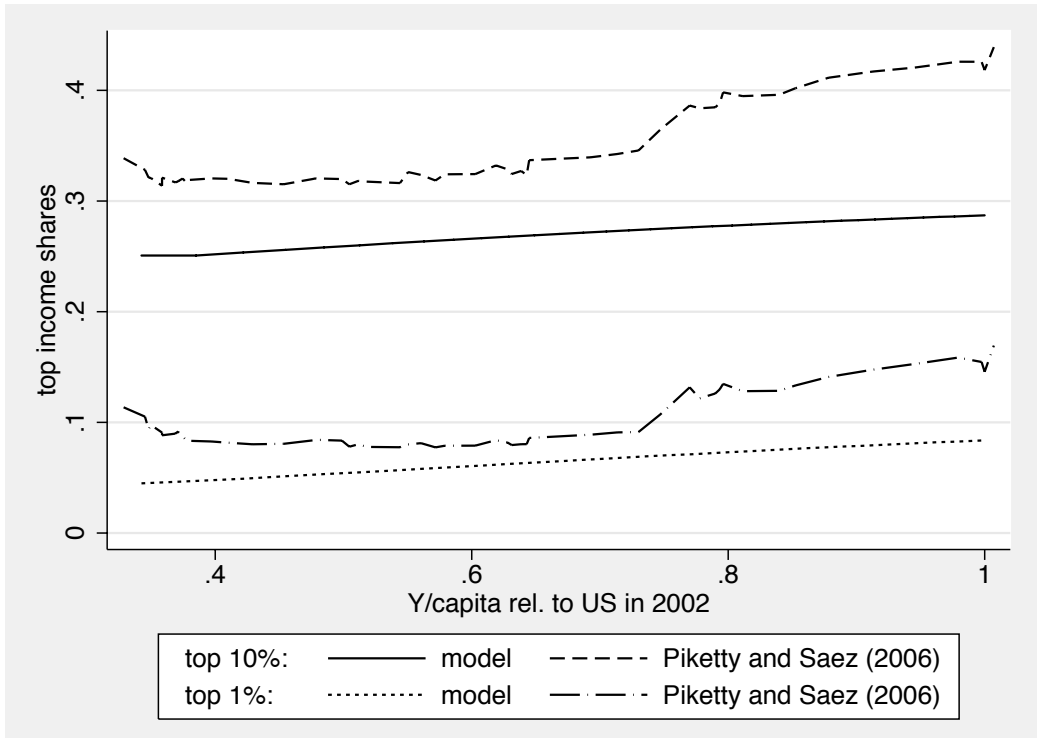

Figure 11: Income concentration at the top, U.S., 1950-2002, model and data Source: Piketty and Saez (2006).

\subsection{Cross-country results}

The model fits the U.S. experience quite well. To evaluate the fit with other countries, each country is assigned the $\bar{M}$ that replicates the output per capita ratio to the U.S. observed in the data. This $\bar{M}$ is then taken to be the country's effective state of technology. ${ }^{36}$ Figure 12 plots the entrepreneurship rate, fraction of small firms, average firm size, firm size dispersion and skewness generated by the model for these levels of $\bar{M}$ against the data. The straight

\footnotetext{
${ }^{36}$ Strictly speaking, $\bar{M}$ of course also captures non-technological sources of income differences like distortions, just as total factor productivity does. It appears reasonable that these also affect entrepreneurs' technological opportunities. Also note that cross-country differences in $\bar{M}$ are taken to be exogenous here; explaining them is beyond the scope of this paper.
} 
line in each graph is the OLS fit discussed in Section 2. The slightly curved lines are the outcomes generated by the model. Quantitative measures of fit are presented in Table 4 .

Given that it was calibrated to the U.S., the model fits the cross-country experience rather well. Of course, as shown in Section 4, its qualitative predictions are in line with the data: the entrepreneurship rate falls with per capita income, while average firm size and size dispersion increase with it. The quantitative exercise reveals that the importance of small firms and firm size skewness in the model also reproduce the patterns observed in the data.

The calibration strategy explains to a large extent why the model does not fit averages of the outcome variables in the data exactly. First, the model is calibrated to fit U.S. statistics, not cross-country averages. Second, the U.S. data calibration targets used are based on more complete data sources than their GEM counterparts shown in the Figure. (This is the key reason for the mean error in fitting average firm size; notice that the calibration target for U.S. average employment exceeds average employment in the GEM data by about 20\% - exactly the mean error of the model in fitting average employment. This also affects the model's fit of dispersion, as measured by the interquartile ratio.) Thirdly, the entrepreneurship rate and the fraction of small firms are not targeted in the calibration. Finally, the model does not fit mean dispersion and skewness for poor countries well for reasons given below.

The quantitative fit to cross-country variation in the firm size distribution is strikingly good for such a stylized model. In particular, the predicted change in the entrepreneurship rate, average firm size and the share of small firms with per capita income are very close to the relationship in the data (Figures 12(a), 12(b) and 12(e)). Quantitative measures of fit indicate that the model fits these aspects basically as well as a regression, which is not restricted in its fit by theory (see the last two columns of Table 4).

The model does slightly less well in terms of predicting firm size dispersion and skewness. It predicts a somewhat too stark relationship between dispersion and income. This also affects how the model fits these variables on average. The main reason for this is that the model predicts that in the poorest countries, $a_{H}$ is very large and almost all firms are small (see also Figure 12(e)). In addition, skill differences do not affect optimal firm size much for low levels of technology, implying low size dispersion even among these small firms. This actually fits with the conditions in many poor countries (see the cluster around Brazil in Figure 12(c)), but neglects other factors like government promotion of certain firms that allow for the existence of some large firms in countries like China, Venezuela or Russia. The model of course cannot pick this up. For the same reason, the model seriously understates skewness in poor countries. In countries with at least half of U.S. GDP, however, these 


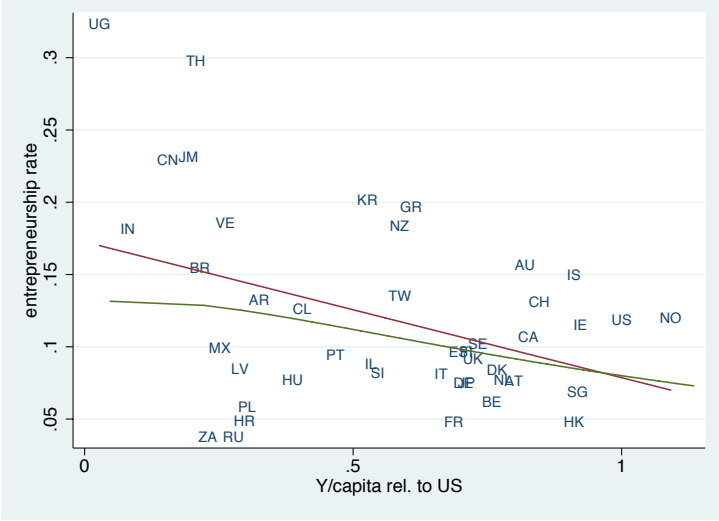

(a) The entrepreneurship rate

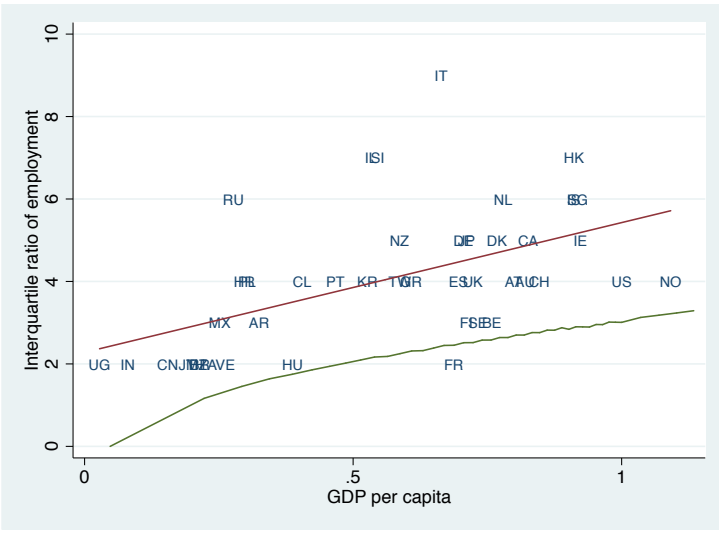

(c) Firm size dispersion

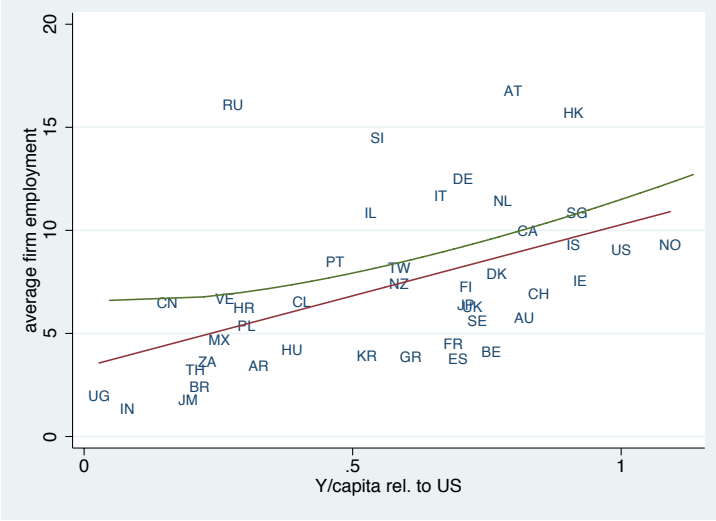

(b) Average employment

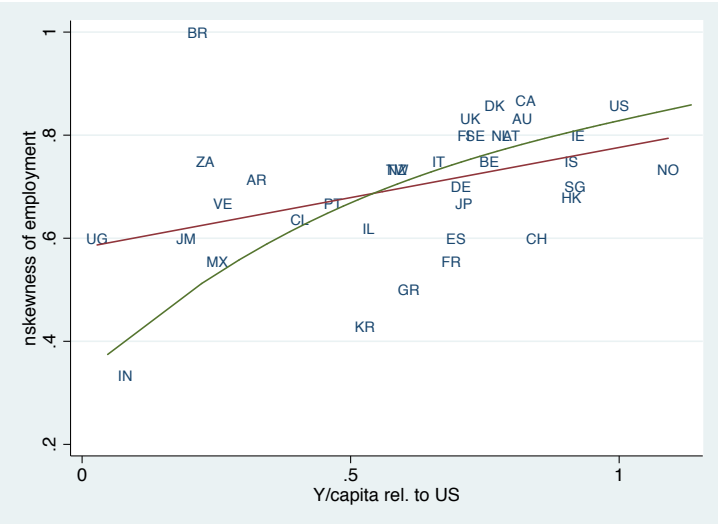

(d) Skewness of firm size

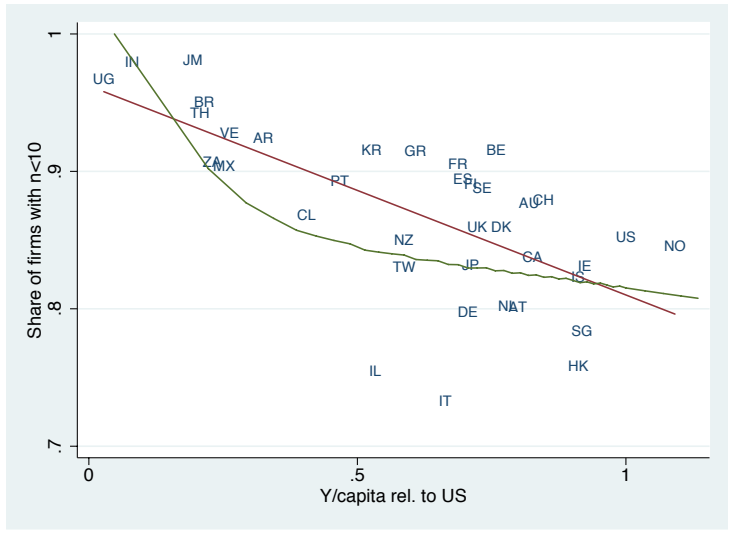

(e) The share of small firms

Figure 12: Entrepreneurship and the firm size distribution versus output per capita: model (curved line) and data (OLS fit)

Notes: Data sources as in Figure 2. 
Table 4: Fit of the model

\begin{tabular}{|c|c|c|c|}
\hline Variable & $\begin{array}{c}\text { mean relative error } \\
(\text { model })\end{array}$ & $\begin{array}{c}\text { RMSD } \\
\text { (model/OLS) }\end{array}$ & $\begin{array}{r}\text { uncentered } R^{2} \\
\text { (model/OLS) }\end{array}$ \\
\hline \multicolumn{4}{|l|}{ All countries: } \\
\hline Entrepreneurship rate & -0.058 & 1.059 & 0.977 \\
\hline Average employment & 0.182 & 1.043 & 0.960 \\
\hline Firm size dispersion & -0.494 & 0.957 & 0.772 \\
\hline Skewness of firm size & -0.086 & 1.559 & 0.989 \\
\hline Share of small firms & 0.011 & 1.114 & 1.000 \\
\hline \multicolumn{4}{|c|}{ Countries with GDP $\geq 0.5$ U.S. GDP: } \\
\hline Firm size dispersion & -0.458 & 1.065 & 0.784 \\
\hline Skewness of firm size & 0.060 & 0.973 & 0.997 \\
\hline Share of small firms & -0.016 & 1.018 & 1.000 \\
\hline
\end{tabular}

Notes: The mean relative error for OLS is zero by construction. RMSD stands for root mean squared deviation. The model RMSD is net of the model error in fitting average levels, which is given by the mean relative error. It thus purely reflects errors in fitting deviations around the mean. The uncentered $R^{2}$ is used instead of the centered one to reflect the mean error in the model predictions. Neither the OLS regression nor the model are reestimated or recalibrated for the sample with less than half of US GDP. This explains how the model fit there can be superior to the OLS fit in one case.

problems diminish, and the model fit of size dispersion and skewness is excellent (lower part of Table 4$).{ }^{37}$

Overall, the quantitative fit is remarkable for a simple, stylized model with few degrees of freedom, calibrated to a different data set (U.S. time series data). In many dimensions, the model fit is within $10 \%$ of the fit of an OLS regression.

\footnotetext{
${ }^{37}$ Can the model explain the positive relationship between the number of registered businesses per capita ("business density") and income observed in e.g. the World Bank Group Entrepreneurship Survey (WBGES) data? Suppose that businesses above a certain size threshold find it optimal to register. This would be observed if the benefits of doing so increase more quickly with size than registration costs. (Indeed, empirical work long identified the informal sector with small firms with for instance less than 20 workers; see e.g. Rauch (1991).) Although the effect of $\bar{M}$ on $a_{L}$ and $a_{H}$ implies that the proportion of large firms increases with income in the model (see also Figure 12(e)), the fraction of the population running a firm above a certain size does not necessarily do so because of the accompanying fall in the entrepreneurship rate. In the U.S. calibration used here, the first effect dominates throughout and the population fraction running firms with more than 20 workers increases monotonically with per capita income. The model thus is qualitatively consistent with business density across countries as measured in the WBGES data. When introducing higher business registration costs in poor countries, as documented by Djankov, La Porta, Lopez-de-Silanes and Shleifer (2002), the relationship becomes even stronger.
} 


\subsection{Alternative explanations fit less well}

Skill-biased change in entrepreneurial technology thus is consistent with patterns in the firm size distribution across countries. This section shows that alternative factors that also look promising at first sight are not consistent with all facts. In particular, while there are several theories that can fit with observed patterns in the entrepreneurship rate and in average firm size, they typically are not consistent with the patterns in dispersion and skewness. This section briefly illustrates the promise and disappointment of regulation, financial frictions, and returns to scale as candidate explanations.

Differences in regulation across countries definitely are a factor that affects the firm size distribution, see e.g. Restuccia and Rogerson (2008) and Hsieh and Klenow (2009). However, while factors related to regulation can explain wedges between firm productivity and size, it is not easy to come up with rules and regulations that explain the set of facts shown in Section 2. For instance, entry regulation, which is more burdensome in poorer countries (Djankov et al. 2002), would imply fewer entrepreneurs and larger firms in poorer countries. The explanation performs better if small firms can escape entry regulation: in this case, entry costs create an "informal" sector, reduce the share of large firms, and may reduce average firm size in poorer countries. However, this effect should mainly affect firms around the threshold where entry regulation becomes effective, and should not affect firms in the right tail of the size distribution. It should thus have only a weak effect on overall dispersion and skewness of the firm size distribution.

Financial frictions could also be thought to stunt the growth of productive firms in lowincome countries. If financial frictions are stronger in poorer countries, they may limit the size of high-productivity firms there, implying smaller firms and less dispersed and skewed firm size. However, for this channel to generate the dispersion patterns observed in the data, it is crucial that financial frictions apply in particular to the most productive firms in a country. This is in contrast to the recent literature on the topic, which stresses that entrepreneurs react to financial frictions by accumulating wealth and may eventually outgrow financing constraints (see in particular Cagetti and De Nardi (2006) and Buera, Kaboski and Shin (2011)). Moreover, this is a partial equilibrium effect. Antunes, Cavalcanti and Villamil (2008) show quantitatively that with an endogenous interest rate, the change in dispersion is ambiguous and quantitatively small in the empirically plausible range of financial frictions. While financial frictions can be important in affecting the allocation of resources among firms and, as a result, aggregate productivity, they are thus unlikely to be the driving force behind the patterns shown in Section $2 .^{38}$

\footnotetext{
${ }^{38}$ In addition, when including the ratio of domestic private credit to GDP (from the IMF International
} 
Finally, the relationship between scale and ability could be modelled differently. In this paper, skill-biased change in entrepreneurial technology is modelled as a relationship between the cost per differentiated activity supervised and ability. This modelling strategy allows taking into account that more able entrepreneurs may have larger span of control than less able ones, while preserving easy aggregation, balanced growth and constant factor income shares. This would not be the case in a setting with explicit heterogeneity in the span of control parameter $\gamma$ as proposed e.g. by Parker and Vissing-Jørgensen (2010) in a different context. In such a setting, an upward trend in $\gamma$ would imply a more skewed distribution of profits and could therefore deliver results consistent with the patterns reported in Section 2. However, it would also have the implication that the profit share of output tends to fall with per capita income. This prediction is hard to assess, but most likely runs counter to the constancy of labor income shares both across countries and within country histories, as documented by Gollin (2002). Roys and Seshadri (2013) generate endogenous variation in the span of control via complementarity between managers' time and worker quality. The resulting structure allows them to fit variation in mean firm size across countries, and several other important features of data on wage dispersion and firm dynamics. Yet, their results are not consistent with the observed pattern of firm size dispersion across countries.

\section{Conclusion}

How and why does the firm size distribution differ across countries? This paper documents that features of the firm size distribution are strongly associated with income per capita. Richer countries have fewer entrepreneurs and fewer small firms. The average, dispersion and skewness of firm size are all larger in richer countries. We should thus not expect the United States to have the same entrepreneurship rate as Brazil.

A simple model of skill-biased change in entrepreneurial technology calibrated to U.S. data can account very well for these patterns. It also shows a convenient way of integrating some results from the micro literature on entrepreneurs and skills into a macroeconomic model. The model provides a good fit although it relies exclusively on technology as the driver of cross-country differences and abstracts from other factors such as regulation or financial constraints. Linking these to the mechanism explored here may make for exciting future work.

Financial Statistics for 2005) as a measure of financial development in the regressions reported in Table 1, estimates for the impact of output per capita are hardly affected. 


\section{References}

Acs, Z. J., Desai, S. and Klapper, L. (2008), "What Does "Entrepreneurship" Data Really Show?', Small Business Economics 31, 265-281.

Akyol, A. and Athreya, K. (2009), 'Self-Employment Rates and Business Size: the Roles of Occupational Choice and Credit Market Frictions', Annals of Finance 5(3-4), 495-519.

Alfaro, L., Charlton, A. and Kanczuk, F. (2008), 'Plant-size distribution and cross- country income differences', NBER Working Paper 14060.

Antunes, A., Cavalcanti, T. and Villamil, A. (2008), 'The Effect of Financial Repression and Enforcement on Entrepreneurship and Economic Development', Journal of Monetary Economics 55(2), 278-297.

Ardagna, S. and Lusardi, A. (2009), Explaining international differences in entrepreneurship: The role of individual characteristics and regulatory constraints, in J. Lerner and A. Schoar, eds, 'International Differences in Entrepreneurship', University Of Chicago Press for the National Bureau of Economic Research, Chicago.

Astebro, T., Chen, J. and Thompson, P. (2011), 'Stars and Misfits: Self-Employment and Labor Market Frictions', Management Science 57(11), 1999-2017.

Autor, D. H., Katz, L. F. and Kearney, M. S. (2008), 'Trends in US wage inequality: revising the revisionists', Review of Economics and Statistics 90(2), 300-323.

Aw, B.-Y. (2002), 'Productivity dynamics of small and medium enterprises in Taiwan', Small Business Economics 18(1), 69-84.

Banerjee, A. V. and Newman, A. F. (1993), 'Occupational Choice and the Process of Development', Journal of Political Economy 101(2), 274-298.

Barseghyan, L. (2008), 'Entry Costs and Cross-Country Differences in Productivity and Output', Journal of Economic Growth 13(2), 145-167.

Bartelsman, E., Haltiwanger, J. and Scarpetta, S. (2004), 'Microeconomic Evidence of Creative Destruction in Industrial and Developing Countries', World Bank Policy Research Working Paper 3464.

Beck, T., Demirgüç-Kunt, A. and Maksimovic, V. (2004), 'Financial and Legal Institutions and Firm Size', World Bank Economic Policy Research Working Paper 2997.

Berry, A., Rodriguez, E. and Sandee, H. (2002), 'Firm and group dynamics in the small and medium enterprise sector in Indonesia', Small Business Economics 18(1), 141-161.

Bertrand, M. (2009), 'CEOs', Annual Review of Economics 1.

Blau, D. M. (1987), 'A time-series analysis of self-employment in the United States', Journal of Political Economy 95(3), 445-467.

Bloom, N., Sadun, R. and Van Reenen, J. (2012), 'Americans do IT better: US multinationals and the productivity miracle', American Economic Review 102(1), 167-201.

Broda, C. and Weinstein, D. E. (2006), 'Globalization and the Gains from Variety', Quarterly Journal of Economics 121(2), 541-585. 
Buera, F. J., Kaboski, J. P. and Shin, Y. (2011), 'Finance and development: A tale of two sectors', American Economic Review 101(5), 1964-2002.

Cagetti, M. and De Nardi, M. (2006), 'Entrepreneurship, Frictions, and Wealth', Journal of Political Economy 114(5), 835-870.

Cain, L. P. and Paterson, D. G. (1986), 'Biased Technical Change, Scale, and Factor Substitution in American Industry, 18501919', Journal of Economic History 46, 153-164.

Carter, S. B., Gartner, S. S., Haines, M. R., Olmstead, A. L., Sutch, R. and Wright, G., eds (2006), Historical Statistics of the United States: Millennial Edition, Cambridge University Press, Cambridge.

Caselli, F. (2005), Accounting for Cross-Country Income Differences, in P. Aghion and S. N. Durlauf, eds, 'Handbook of Economic Growth', North Holland, Amsterdam.

Cummins, J. G. and Violante, G. L. (2002), 'Investment-Specific Technical Change in the United States (1947-2000): Measurement and Macroeconomic Consequences', Review of Economic Dynamics 5(2), 243-284.

Djankov, S., La Porta, R., Lopez-de-Silanes, F. and Shleifer, A. (2002), 'The Regulation of Entry', Quarterly Journal of Economics 117(1), 1-37.

Elsby, M. W. L., Hobijn, B. and Şahin, A. (2013), 'The Decline of the U.S. Labor Share', Brookings Papers on Economic Activity .

Evans, D. S. and Leighton, L. S. (1989), 'Some Empirical Aspects of Entrepreneurship', American Economic Review 79(3), 519-535.

Faggio, G., Salvanes, K. G. and Van Reenen, J. (2010), 'The evolution of inequality in productivity and wages: Panel data evidence', Industrial and Corporate Change 19(6), 19191951.

Felbermayr, G., Impullitti, G. and Prat, J. (2013), 'Wage Inequality, Firm Dynamics, and International Trade', mimeo, CNRS .

Frydman, C. (2007), 'Rising Through the Ranks: The evolution of the market for corporate executives, 1936-2003', mimeo, MIT .

Gabaix, X. and Landier, A. (2008), 'Why Has CEO Pay Increased So Much?', Quarterly Journal of Economics 123(1), 49-100.

Galí, J. (1995), 'Product diversity, endogenous markups, and development traps', Journal of Monetary Economics 36(1), 39-63.

García-Santana, M. and Pijoan-Mas, J. (2012), 'The reservation laws in india and the misallocation of production factors', mimeo, Cemfi .

García-Santana, M. and Ramos, R. (2013), 'Distortions and the size distribution of plants: Evidence from cross-country data', mimeo, Cemfi .

Garicano, L. (2000), 'Hierarchies and the Organization of Knowledge in Production', Journal of Political Economy 108(5), 874-904.

Gindling, T. H. and Newhouse, D. (2012), 'Self-employment in the developing world', World Bank Policy Research Working Paper (6201). 
Gollin, D. (2002), 'Getting income shares right', Journal of Political Economy 110(2), 458474.

Gollin, D. (2007), 'Nobody's business but my own: Self-employment and small enterprise in economic development', Journal of Monetary Economics 55(2), 219-233.

Greenwood, J., Hercowitz, Z. and Krusell, P. (1997), 'Long-run implications of investmentspecific technological change', American Economic Review 87(3), 342-362.

Grossman, G. M., Helpman, E. and Kircher, P. (2013), 'Matching and sorting in a global economy', mimeo, University of Edinburgh .

Hamilton, B. H. (2000), 'Does Entrepreneurship Pay? An Empirical Analysis of the Returns to Self-Employment', Journal of Political Economy 108(3), 604-631.

Heston, A., Summers, R. and Aten, B. (2009), 'Penn World Table Version 6.3', Center for International Comparisons of Production, Income and Prices at the University of Pennsylvania.

Hipple, S. (2004), 'Self-employment in the United States: an update', Monthly Labor Review $127(7), 13-23$.

Hipple, S. (2010), 'Self-employment in the United States', Monthly Labor Review 133(9), 1732.

Hopenhayn, H. (1992), 'Entry, Exit, and Firm Dynamics in Long Run Equilibrium', Econometrica 60(5), 1127-1150.

Hornstein, A., Krusell, P. and Violante, G. (2005), The Effects of Technical Change on Labor Market Inequalities, in P. Aghion and S. N. Durlauf, eds, 'Handbook of Economic Growth', Vol. 1, Elsevier, Amsterdam, pp. 1275-1370.

Hsieh, C.-T. and Klenow, P. J. (2009), 'Misallocation and Manufacturing TFP in China and India', Quarterly Journal of Economics 124, 1403-1448.

Hurst, E. and Pugsley, B. W. (2011), 'What Do Small Businesses Do?', Brookings Papers on Economic Activity .

James, J. A. and Skinner, J. S. (1985), 'The Resolution of the Labor-Scarcity Paradox', Journal of Economic History 45, 513-540.

Jones, C. I. (1995), 'R\&D-Based Models of Economic Growth', Journal of Political Economy 103(4), 759-784.

Jovanovic, B. (1994), 'Firm Formation with Heterogeneous Management and Labor Skills', Small Business Economics 6, 185-191.

Jovanovic, B. and Rousseau, P. L. (2008), 'Specific capital and technological variety', Journal of Human Capital 2(2), 129-153.

Kaplan, S. N. and Rauh, J. (2013), 'Its the Market: The Broad-Based Rise in the Return to Top Talent', Journal of Economic Perspectives 27(3), 35-56.

Katz, L. F. and Murphy, K. M. (1992), 'Changes in Relative Wages, 1963-1987: Supply and Demand Factors', Quarterly Journal of Economics 107(1), 35-76. 
Kehrig, M. (2012), 'Are recessions cleansing or sullying? evidence from the cyclicality of productivity dispersion', mimeo, UT Austin .

Kihlstrom, R. and Laffont, J.-J. (1979), 'A General Equilibrium Entrepreneurial Theory of Firm Formation Based on Risk Aversion', Journal of Political Economy 87(4), 719-748.

King, R. G., Plosser, C. I. and Rebelo, S. T. (1988), 'Production, Growth and Business Cycles: I. The Basic Neoclassical Model', Journal of Monetary Economics 21(2-3), 195232 .

Klapper, L., Laeven, L. and Rajan, R. (2006), 'Entry regulation as a barrier to entrepreneurship', Journal of Financial Economics 82(3), 591-629.

Krusell, P., Ohanian, L. E., Rios-Rull, J.-V. and Violante, G. (2000), 'Capital-Skill Complementarity and Inequality: a Macroeconomic Analysis', Econometrica 68(5), 1029-1053.

Lazear, E. P. (2004), 'Balanced Skills and Entrepreneurship', American Economic Review Papers and Proceedings 94(2), 208-211.

Lazear, E. P. (2005), 'Entrepreneurship', Journal of Labor Economics 23(4), 649-680.

Lloyd-Ellis, H. (1999), 'Endogenous technological change and wage inequality', American Economic Review 89(1), 47-77.

Lloyd-Ellis, H. and Bernhardt, D. (2000), 'Enterprise, Inequality and Economic Development', Review of Economic Studies 67(1).

Lucas, R. E. (1978), 'On the size distribution of business firms', Bell Journal of Economics 9, 508-523.

Michaels, G. (2007), 'The division of labour, coordination, and the demand for information processing', CEPR Discussion Paper .

Moscoso Boedo, H. J. and Mukoyama, T. (2012), 'Evaluating the Effects of Entry Regulations and Firing Costs on International Income Differences', Journal of Economic Growth $\mathbf{1 7}(2), 143-170$.

Murphy, K. J. and Zabojnik, J. (2004), 'CEO pay and appointments: A market-based explanation for recent trends', American Economic Review 94(2), 192-196.

Murphy, K., Shleifer, A. and Vishny, R. (1991), 'The allocation of talent: implications for growth', The Quarterly Journal of Economics 106(2), 503-530.

Nugent, J. B. and Yhee, S.-J. (2002), 'Small and medium enterprises in Korea: Achievements, constraints and policy issues', Small Business Economics 18(1), 85-119.

Ohyama, A. (2012), 'Entrepreneurship and Advanced Technical Knowledge', mimeo, University of Illinois at Urbana-Champaign .

Parker, J. A. and Vissing-Jørgensen, A. (2010), 'The Increase in Income Cyclicality of HighIncome Households and Its Relation to the Rise in Top Income Shares', Brookings Papers on Economic Activity (Fall), 1-55.

Piketty, T. and Saez, E. (2006), 'The Evolution of Top Incomes: a Historical and International Perspective', American Economic Review 96(2), 200-205. 
Poschke, M. (2010), 'The regulation of entry and aggregate productivity', The Economic Journal 120(549), 1175-1200.

Poschke, M. (2013a), 'The decision to become an entrepreneur and the firm size distribution: A unifying framework for policy analysis', IZA Discussion Paper 7757.

Poschke, M. (2013b), 'Who Becomes an Entrepreneur? Labor Market Prospects and Occupational Choice', Journal of Economic Dynamics and Control 37, 693-710.

Quadrini, V. (2009), 'Entrepreneurship in macroeconomics', Annals of Finance 5(3-4), 295311.

Rajan, R. G. and Wulf, J. (2006), 'Are perks purely managerial excess?', Journal of Financial Economics 79(1), 1-33.

Rauch, J. E. (1991), 'Modelling the informal sector formally', Journal of Development Economics 35(1), 33-47.

Restuccia, D. and Rogerson, R. (2008), 'Policy Distortions and Aggregate Productivity with Heterogeneous Establishments', Review of Economic Dynamics 11(4), 707-720.

Restuccia, D., Yang, D. and Zhu, X. (2008), 'Agriculture and Aggregate Productivity: A Quantitative Cross-Country Analysis', Journal of Monetary Economics 55(2), 234-50.

Reynolds, P., Bosma, N., Autio, E., Hunt, S., De Bono, N., Servais, I., Lopez-Garcia, P. and Chin, N. (2005), 'Gobal Entrepreneurship Monitor: Data Collection Design and Implementation 1998-2003', Small Business Economics 24, 205-231.

Romer, P. M. (1987), 'Growth based on increasing returns due to specialization', American Economic Review 77(2), 56-62.

Rosen, S. (1982), 'Authority, Control, and the Distribution of Earnings', Bell Journal of Economics 13(2), 311-323.

Roys, N. and Seshadri, A. (2013), 'Economic development and the organization of production', mimeo, University of Wisconsin, Madison .

Samaniego, R. M. (2006), 'Industrial subsidies and technology adoption in general equilibrium', Journal of Economic Dynamics and Control 30(9-10), 1589-1614.

Scopp, T. S. (2003), 'The Relationship Between the 1990 Census and Census 2000 Industry and Occupation Classification Systems', U.S. Census Bureau Technical Paper 65.

Summers, R. and Heston, A. (1991), 'The Penn World Table (Mark 5): An Expanded Set of International Comparisons: 1950-1988', Quarterly Journal of Economics 56, 327-368.

Terviö, M. (2008), 'The Difference that CEOs Make: An Assignment Model Approach', American Economic Review 98(3), 642-668.

Teulings, C. (1995), 'The Wage Distribution in a Model of the Assignment of Skills to Jobs', Journal of Political Economy 103(2), 280-315.

Tomlin, B. and Fung, L. (2012), 'Exchange Rate Movements and Productivity Distribution', Bank of Canada Working Paper 2010-25.

Tybout, J. R. (2000), 'Manufacturing Firms in Developing Countries: How Well Do They Do, and Why?', Journal of Economic Literature 38(1), 11-44. 
Urata, S. and Kawai, H. (2002), 'Technological progress by small and medium enterprises in Japan', Small Business Economics 18(1), 53-67.

U.S. Department of Commerce (1975), Historical Statistics of the United States: Colonial Times to 1970, U.S. Government Printing Office, Washington, DC.

Vereshchagina, G. and Hopenhayn, H. (2009), 'Risk taking by entrepreneurs', American Economic Review 99(5), 1808-1830.

Weir, D. R. (1992), A Century of U.S. Unemployment, 1890-1990, in R. L. Ransom, R. Sutch and S. B. Carter, eds, 'Research in Economic History', JAI Press, Greenwich, pp. 341343.

Wiboonchutikula, P. (2002), 'Small and medium enterprises in Thailand: Recent trends', Small Business Economics 18(1), 211-224. 


\section{Appendix}

\section{A Additional Tables and Figures}

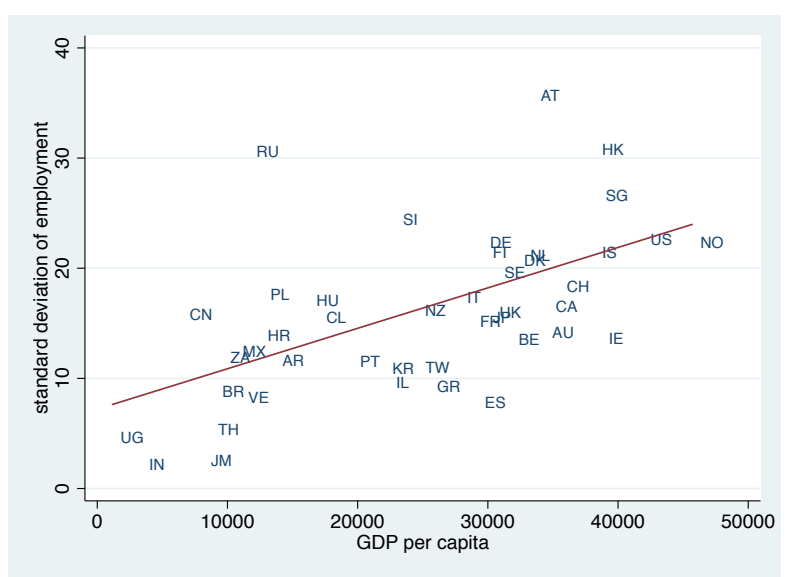

(a) Small and medium sized firms (GEM, $n<300)$

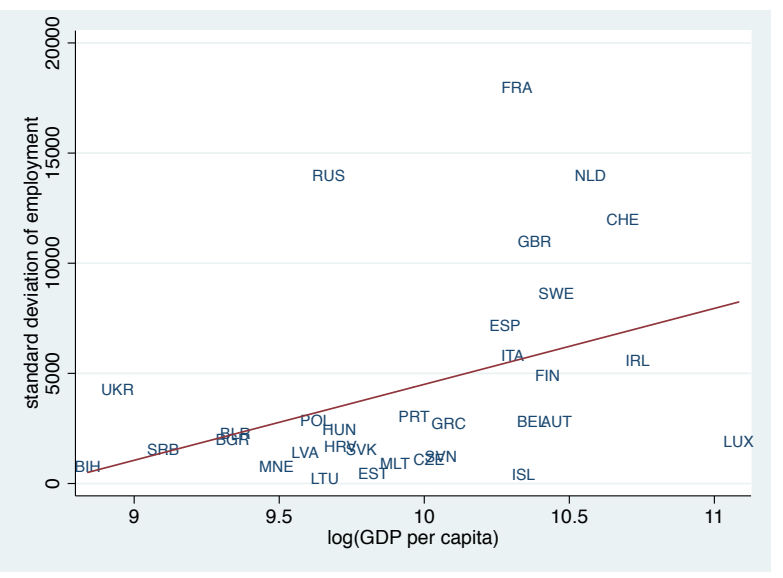

(b) Large firms (Amadeus, $n \geq 300$ )

Figure 13: Standard deviation of employment and per capita income.

Notes: Data sources as in Figure 3. Regression results underlying the OLS line of best fit plotted in the figure are reported in Table 5.

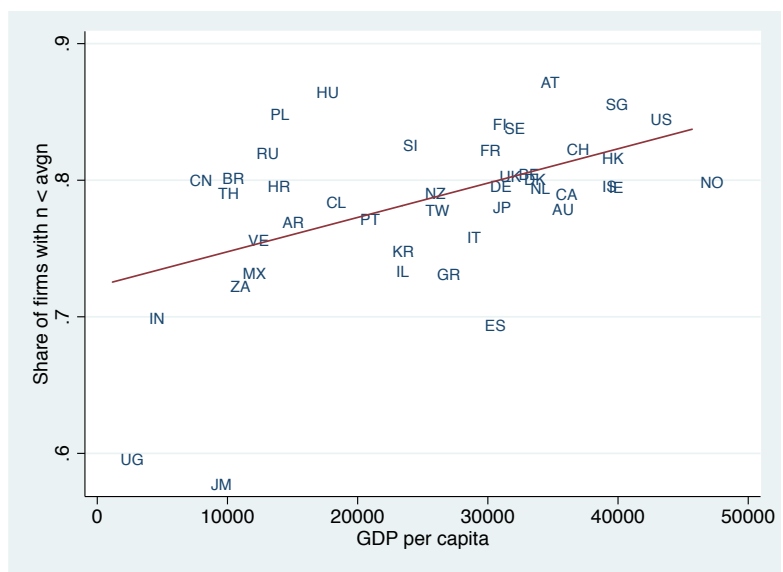

(a) Small and medium sized firms (GEM, $n<300)$

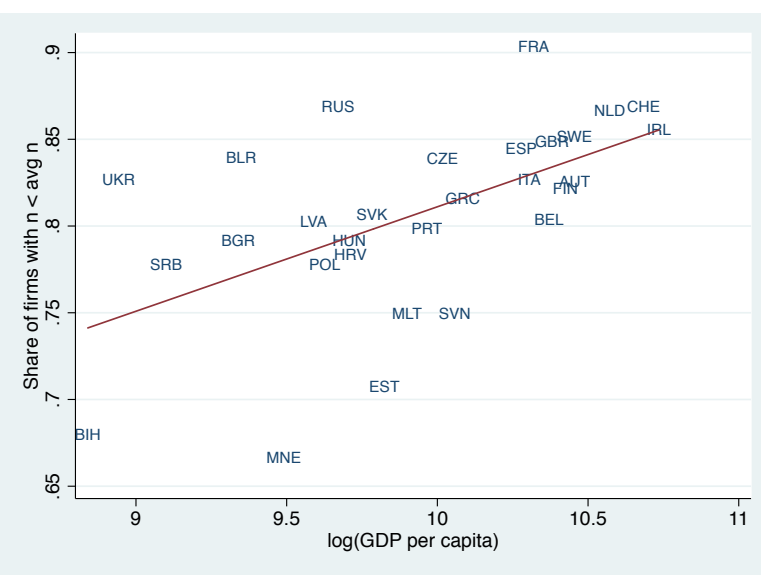

(b) Large firms (Amadeus, $n \geq 300$ )

Figure 14: Skewness of firm size and per capita income.

Notes: Data sources as in Figure 2. Skewness is measured as the fraction of firms with less than average size. Regression results underlying the OLS line of best fit plotted in the figure are reported in Table 5. Panel (b) excludes Iceland and Lithuania, which have very low values of skewness, and Luxembourg, where skewness in 2007 is much lower than in subsequent years. 
Table 5: The firm size distribution and per capita income - additional moments.

\begin{tabular}{lccccccc}
\hline \multirow{2}{*}{ Moment } & \multicolumn{3}{c}{ GEM data $(n<300)$} & & \multicolumn{3}{c}{ Amadeus data $(n \geq 300)$} \\
\cline { 2 - 3 } \cline { 7 - 8 } & Coeff. & $\mathrm{SE}$ & $\mathrm{R}^{2}$ & & Coeff. & $\mathrm{SE}$ & $\mathrm{R}^{2}$ \\
\hline $\begin{array}{c}\text { Standard deviation } \\
\text { of employment }\end{array}$ & $5.661^{* * *}$ & $(1.273)$ & 0.325 & & $3447.5^{* *}$ & $(1451.2)$ & 0.158 \\
$\begin{array}{c}\text { Fraction of firms below } \\
\text { average employment }\end{array}$ & $0.048^{* * *}$ & $(0.010)$ & 0.350 & $0.042^{* *}$ & $(0.018)$ & 0.164 \\
\hline
\end{tabular}

Notes: Data sources as in Figure 3. The table shows coefficients from bivariate regressions of each moment on log GDP per capita, the standard errors on those coefficients, and the $\mathrm{R}^{2}$ for each regression. A constant is also included in each regression (coefficient not reported). ${ }^{* * *}\left({ }^{* *}\right)\left[{ }^{*}\right]$ denotes statistical significance at the $1 \%(5 \%)[10 \%]$ level.

Table 6: The firm size distribution and per capita income - controlling for industry (Amadeus data, $n \geq 300)$.

\begin{tabular}{lcrc}
\hline Moment & Coeff. & \multicolumn{1}{c}{$\mathrm{SE}$} & $\mathrm{R}^{2}$ \\
\hline Average employment & $528.9^{* * *}$ & $(152.9)$ & 0.282 \\
Standard deviation of employment & $1136.5^{* *}$ & $(446.6)$ & 0.222 \\
Fraction of firms below average size & $0.022^{* * *}$ & $(0.005)$ & 0.185 \\
Employment distribution: & & & \\
$p_{10}$ & 3.7 & $(3.4)$ & 0.184 \\
$p_{25}$ & $33.5^{* * *}$ & $(7.9)$ & 0.261 \\
$p_{50}$ & $112.4^{* * *}$ & $(21.2)$ & 0.343 \\
$p_{75}$ & $542.2^{* * *}$ & $(149.4)$ & 0.199 \\
$p_{90}$ & $2189.3^{* * *}$ & $(567.1)$ & 0.270 \\
\hline Test that... & p-value & & \\
coefficients equal at all $p_{i}$ & 0.000 & & \\
$b\left(p_{25}\right)>b\left(p_{10}\right)$ & 0.000 & & \\
$b\left(p_{50}\right)>b\left(p_{25}\right)$ & 0.000 & & \\
$b\left(p_{75}\right)>b\left(p_{50}\right)$ & 0.003 & & \\
$b\left(p_{90}\right)>b\left(p_{75}\right)$ & 0.001 & & \\
\hline
\end{tabular}

Notes: Data sources as in Figure 2. Detailed industry information is only available in the Amadeus data. The table shows coefficients from bivariate regressions of each moment for a industry/country pair on country $\log$ GDP per capita. It also shows the standard errors on those coefficients, and the $\mathrm{R}^{2}$ for each regression. Each regression also includes a constant and a full set of dummies for 4-digit NAICS 2007 industries (coefficients not reported). Industry/country pairs containig at least 5 firms are included in the regression. Results are similar if this cutoff is lowered to $3 . p_{i}$ stands for the $i^{\text {th }}$ percentile of the employment distribution. $b\left(p_{i}\right)$ refers to the coefficient on $\log$ GDP per capita in the regression of $p_{i}$ on $\log$ GDP per capita. ${ }^{* * *}\left({ }^{* *}\right)\left[{ }^{*}\right]$ denotes statistical significance at the $1 \%(5 \%)[10 \%]$ level. 


\section{B Proofs and derivations (not for publication)}

\section{B.1 Equilibrium}

Recall:

$$
\begin{aligned}
\pi(a, \bar{M}) & =(1-\gamma)\left(\frac{w}{\gamma}\right)^{\frac{-\gamma}{1-\gamma}} \bar{M}^{\eta a} \\
w(\bar{M}) & =\gamma\left[\frac{B}{N} \int \nu(a) \bar{M}^{\eta a} \mathrm{~d} a\right]^{1-\gamma}
\end{aligned}
$$

where $\eta \equiv \frac{1}{\sigma-1} \frac{\gamma}{1-\gamma}>1$, and where here and in the following the integral is over the set of entrepreneurs, $a \in\left[0, a_{L}\right] \vee a \in\left[a_{H}, \bar{a}\right]$. (LM) is the labor market clearing condition, and one key equilibrium condition. The other one is the free entry/optimal occupational choice condition $\pi\left(a_{i}, \bar{M}\right)=w a_{i}$, which given the shape of the profit and earnings functions holds at $a_{i}=a_{L}, a_{H}$. Note that this can be transformed to yield

$$
w=\left[(1-\gamma) \frac{\bar{M}^{\eta a_{L}}}{a_{L}}\right]^{1-\gamma} \gamma^{\gamma}=\left[(1-\gamma) \frac{\bar{M}^{\eta a_{H}}}{a_{H}}\right]^{1-\gamma} \gamma^{\gamma}
$$

Note that since only a differs across individuals, this implies $\bar{M}^{\eta a_{L}} / a_{L}=\bar{M}^{\eta a_{H}} / a_{H}$. Thus, define an implicit function $m_{x}\left(a_{L}\right)$ that maps from $a_{L}$ to $a_{H}$. What does $m_{x}(\cdot)$ look like? It is convex, U-shaped on the positive domain, with a minimum at $1 /(\eta \ln \bar{M})$. Any $\bar{M}$ implies a $w$, which implies an $a_{L}$, which lies on the left, downward-sloping arm of the function, and an $a_{H}$, which lies on its right, upward-sloping arm. Therefore, for any $\bar{M}, a_{L}<1 /(\eta \ln \bar{M})<a_{H}$.

To obtain equilibrium $a_{L}$ and $w$, plot two functions in $a_{L}, w$ space. First, the left, downward-sloping arm of FEC. This shows the $a_{L}$ implied by any $w$, given $\bar{M}$. Second, LM, interpreting the market-clearing wage as a function of $a_{L}$. How does $w$ change with $a_{L}$ ? For given $\bar{M}$, consider raising $a_{L}$. From FEC, this implies reducing $a_{H}$. These two changes imply more firms, therefore larger labor demand. They also imply less labor supply. As a consequence, a higher wage is required to equilibrate the labor market: LM is upwardsloping. The intersection of FEC and LM gives equilibrium $w$ and $a_{L}$. Equilibrium $a_{H}$ can then be read off FEC.

\section{B.2 Development and occupational choice: $\bar{M} \uparrow$}

Changes in (LM) and (FEC) with development. To see what happens with increases in $\bar{M}$, analyze how LM and FEC change, given $a_{L}$. The derivative of LM with respect to $\bar{M}$, given $a_{L}$, is

$$
\begin{aligned}
& \gamma(1-\gamma)\left(\frac{1}{N}\right)^{1-\gamma}\left[\int \phi(a) \bar{M}^{\eta a} \mathrm{~d} a\right]^{-\gamma} \eta \int \phi(a) a \bar{M}^{\eta a-1} \\
& =(1-\gamma) \eta \frac{w}{\bar{M}} \int \phi(a) a \bar{M}^{\eta a}\left[\int \phi(a) \bar{M}^{\eta a}\right]^{-1} .
\end{aligned}
$$


The derivative of FEC with respect to $\bar{M}$, given $a_{L}$, is

$$
\gamma^{\gamma}(1-\gamma) \eta a_{L}\left[(1-\gamma) \frac{\bar{M}^{\eta a_{L}}}{a_{L}}\right]^{1-\gamma} \frac{1}{\bar{M}}=(1-\gamma) \eta a_{L} \frac{w}{\bar{M}}
$$

Both curves shift up as $\bar{M}$ rises, implying that the wage rate increases with $\bar{M}$. The difference between the two derivatives is

$$
\Delta \equiv(1-\gamma) \eta \frac{w}{\bar{M}}\left[\int \phi(a) a \bar{M}^{\eta a}\left[\int \phi(a) \bar{M}^{\eta a}\right]^{-1}-a_{L}\right]
$$

If this equals zero, FEC and LM shift up by the same amount in response to an increase in $\bar{M}$, and $a_{L}$ does not change. If it is positive, LM shifts up more, and $a_{L}$ needs to decrease for both FEC and LM to hold. At the old $a_{L}$, the $w$ implied by LM would exceed that implied by FEC: this means that at the wage that clears the labor market, the $a_{L}$ does not imply an optimal occupational choice; more marginal entrepreneurs would like to become workers, so $a_{L}$ needs to fall for both LM and FEC to hold. If the difference is negative, $a_{L}$ needs to rise for both FEC and LM to hold.

$\mathbf{a}_{\mathbf{L}}(\overline{\mathbf{M}}=\mathbf{1})$. How does $a_{L}$ evolve with $\bar{M}$ ? Note that the term in square brackets can take on negative and positive values. For instance, at the extreme of $\bar{M}=1$, the FEC and LM imply

$$
\begin{aligned}
\left(\frac{1-\gamma}{a_{L}}\right)^{1-\gamma} \gamma^{\gamma} & =\gamma\left(\frac{B}{N}\right)^{1-\gamma} \\
\Rightarrow \frac{N}{B} & =\frac{\gamma}{1-\gamma} a_{L}
\end{aligned}
$$

With $\bar{M}=1$, the ratio of integrals also equals $N / B$, implying that the term in square brackets equals $-1 /(1-\gamma) a_{L}<0$.

$\Delta$ increases with $\bar{M}$ (Lemma 1). $\Delta$ changes with $\bar{M}$. Its derivative with respect to $\bar{M}$ is

$$
\begin{aligned}
\frac{\partial \Delta}{\partial \bar{M}} & =\frac{w}{\bar{M}} \frac{\eta}{\bar{M}} \frac{\int \phi(a) \bar{M}^{\eta a} \mathrm{~d} a \cdot \int \phi(a) a^{2} \bar{M}^{\eta a} \mathrm{~d} a-\left(\int \phi(a) a \bar{M}^{\eta a} \mathrm{~d} a\right)^{2}}{\left(\int \phi(a) \bar{M}^{\eta a} \mathrm{~d} a\right)^{2}} \\
& +\left[\int \phi(a) a \bar{M}^{\eta a}\left[\int \phi(a) \bar{M}^{\eta a}\right]^{-1}-a_{L}\right] w \frac{(1-\gamma) \eta \int \phi(a) a \bar{M}^{\eta a}\left[\int \phi(a) \bar{M}^{\eta a}\right]^{-1}-1}{\bar{M}^{2}}
\end{aligned}
$$

The first term is weakly positive by the Cauchy-Schwartz inequality, and strictly so if there is dispersion in the productivity of active firms. This implies that $\int \phi(a) a \bar{M}^{\eta a}\left[\int \phi(a) \bar{M}^{\eta a}\right]^{-1}$ increases in $\bar{M}$. Now consider the case where $\bar{M}$ is such that $a_{L}=\frac{\sigma-1}{\gamma}=\frac{1}{\eta} \frac{1}{1-\gamma}$. In this case, 
the second term becomes

$$
\frac{w}{a_{L} \bar{M}^{2}}\left[\int \phi(a) a \bar{M}^{\eta a}\left[\int \phi(a) \bar{M}^{\eta a}\right]^{-1}-\frac{\sigma-1}{\gamma}\right]^{2} .
$$

In addition, from the FEC,

$$
w=\bar{M} \gamma^{\gamma} \eta^{\gamma-1}
$$

and the elasticity of $w(F E C)$ with respect to $\bar{M}$ is 1 for $\bar{M}$ s.t. $a_{L}=\frac{\sigma-1}{\gamma}$. Using LM, the elasticity of $w$ with respect to $\bar{M}$ is

$$
\frac{\gamma}{\sigma-1} \int \phi(a) a \bar{M}^{\eta a}\left[\int \phi(a) \bar{M}^{\eta a}\right]^{-1} .
$$

Using these two expressions shows that the second term in $\partial \Delta / \partial \bar{M}$ is 0 at an equilibrium with $a_{L}=\frac{\sigma-1}{\gamma}$. Since both parts of the second term increase in $\bar{M}$, they are both positive (negative) for $a_{L}>(<) \frac{\sigma-1}{\gamma}$, implying that $\partial \Delta / \partial \bar{M}$ is always positive.

The evolution of $a_{L}$ (Corollary 2): Since $\Delta$ is negative for $\bar{M}=1$ but increases in $\bar{M}, a_{L}$ follows the following path: It first rises, as the w implied by FEC increases more than that implied by LM in response to an increase in $\bar{M}$, and then falls, as the relationship inverts.

The derivative of $a_{i}$ wrt $\bar{M}$ (Equations (7) and (8)). We can also use the FEC to derive another useful expression describing the evolution of $a_{L}$ and $a_{H}$. Take the FEC and take the derivative with respect to $\bar{M}$, not keeping $a_{L}$ constant. Note that

$$
\frac{\partial \bar{M}^{\eta a_{L}(\bar{M})}}{\bar{M}}=\bar{M}^{\eta a_{L}}\left[\frac{\eta a_{L}}{\bar{M}}+\eta a_{L}^{\prime} \ln \bar{M}\right]
$$

Taking the derivative of FEC with respect to $\bar{M}$ then yields

$$
\begin{aligned}
w^{\prime} & =\gamma^{\gamma}(1-\gamma)\left[(1-\gamma) \frac{\bar{M}^{\eta a_{i}}}{a_{i}}\right]^{-\gamma}(1-\gamma) \frac{a_{i} \bar{M}^{\eta a_{i}}\left[\frac{\eta a_{i}}{\bar{M}}+\eta a_{i}^{\prime} \ln \bar{M}\right]-\bar{M}^{\eta a_{i}} a_{i}^{\prime}}{a_{i}^{2}} \\
& =\gamma^{\gamma}(1-\gamma)\left[(1-\gamma) \frac{\bar{M}^{\eta a_{i}}}{a_{i}}\right]^{1-\gamma} \frac{a_{i}\left[\frac{\eta a_{i}}{M}+\eta a_{i}^{\prime} \ln \bar{M}\right]-a_{i}^{\prime}}{a_{i}} \\
& =(1-\gamma) w \frac{a_{i}\left[\frac{\eta a_{i}}{M}+\eta a_{i}^{\prime} \ln \bar{M}\right]-a_{i}^{\prime}}{a_{i}} \\
\varepsilon(w, \bar{M}) & =(1-\gamma)\left[\eta\left(a_{i}+\bar{M} a_{i}^{\prime} \ln \bar{M}\right)-\bar{M} a_{i}^{\prime} / a_{i}\right] \\
a_{i}^{\prime} & =\frac{1}{\bar{M}} \frac{\varepsilon(w, \bar{M}) /(1-\gamma)-\eta a_{i}}{\eta \ln \bar{M}-1 / a_{i}}
\end{aligned}
$$


Note that given the properties of the function $m_{x}(\cdot)$, the denominator is negative for $a_{L}$ and positive for $a_{H}$. If the numerator is positive, a marginal entrepreneur benefits more from wage growth (the change in the outside option) than from the productivity growth brought about by the increase in $\bar{M}$, and exits. This implies a decline in $a_{L}$ (numerator positive, denominator negative) or an increase in $a_{H}$ (both positive).

This expression also allows linking the change in $a_{L}$ and in $a_{H}$. Since the elasticity is the same,

$$
\begin{aligned}
(1-\gamma)\left[\eta\left(a_{L}+\bar{M} a_{L}^{\prime} \ln \bar{M}\right)-\bar{M} a_{L}^{\prime} / a_{L}\right] & =(1-\gamma)\left[\eta\left(a_{H}+\bar{M} a_{H}^{\prime} \ln \bar{M}\right)-\bar{M} a_{H}^{\prime} / a_{H}\right] \\
\eta a_{L}+a_{L}^{\prime} \bar{M}\left(\eta \ln \bar{M}-1 / a_{L}\right) & =\eta a_{H}+a_{H}^{\prime} \bar{M}\left(\eta \ln \bar{M}-1 / a_{H}\right) \\
a_{H}^{\prime} & =\frac{\eta\left(a_{L}-a_{H}\right)+a_{L}^{\prime} \bar{M}\left(\eta \ln \bar{M}-1 / a_{L}\right)}{\bar{M}\left(\eta \ln \bar{M}-1 / a_{H}\right)} \\
& =\eta \frac{a_{L}-a_{H}}{\bar{M}\left(\eta \ln \bar{M}-1 / a_{H}\right)}+a_{L}^{\prime} \frac{\bar{M}\left(\eta \ln \bar{M}-1 / a_{L}\right)}{\bar{M}\left(\eta \ln \bar{M}-1 / a_{H}\right)}
\end{aligned}
$$

Since, by the properties of $m_{x}$, the last fraction is negative, $a_{H}^{\prime}$ is a decreasing function of $a_{L}^{\prime}$. This is not only due to the shape of $m_{x}(\cdot)$, as that function itself shifts as $\bar{M}$ changes. Because $a_{L}<a_{H}$, the intercept is negative. So, for $a_{L}^{\prime} \geq 0, a_{H}^{\prime}<0$. As $a_{L}^{\prime}$ falls, $a_{H}^{\prime}$ might eventually reach positive territory.

Proposition 3. As a result, development can be partitioned in three phases:

$$
\begin{array}{ll}
\text { P0 : } & a_{L}^{\prime}>0, a_{H}^{\prime}<0 \\
\text { P1 : } & a_{L}^{\prime}<0, a_{H}^{\prime}<0 \\
\text { P2 : } & a_{L}^{\prime}<0, a_{H}^{\prime}>0
\end{array}
$$

As $\bar{M}$ increases, the economy traverses the three phases. For $\bar{M}=1$, it is in $\mathbf{P 0 .}$ 